\title{
Optimizing adsorption of fluoride from water by modified banana peel dust using response surface modelling approach
}

\author{
Ria Bhaumik • Naba Kumar Mondal
}

Received: 24 December 2013/Accepted: 3 June 2014/Published online: 18 June 2014

(C) The Author(s) 2014. This article is published with open access at Springerlink.com

\begin{abstract}
The present work highlighted the effective application of banana peel dust (BPD) for removal of fluoride $\left(\mathrm{F}^{-}\right)$from aqueous solution. The effects of operating parameters such as $\mathrm{pH}$, initial concentration, adsorbent dose, contact time, agitation speed and temperature were analysed using response surface methodology. The significance of independent variables and their interactions were tested by the analysis of variance and $t$ test statistics. Experimental results revealed that BPD has higher $\mathrm{F}^{-}$ adsorption capacity $(17.43,26.31$ and $39.5 \mathrm{mg} / \mathrm{g})$. Fluoride adsorption kinetics followed pseudo-second-order model with high correlation of coefficient value (0.998). On the other hand, thermodynamic data suggest that adsorption is favoured at lower temperature, exothermic in nature and enthalpy driven. The adsorbents were characterised through scanning electron microscope, Fourier transform infrared spectroscopy and point of zero charges $\left(\mathrm{pH}_{\mathrm{ZPC}}\right)$ ranges from $\mathrm{pH}$ 6.2-8.2. Finally, error analysis clearly demonstrates that all three adsorbents are well fitted with Langmuir isotherm compared to the other isotherm models. The reusable properties of the material support further development for commercial application purpose.
\end{abstract}

Keywords Fluoride - Optimization - Langmuir model · Error analysis · Pseudo-second-order kinetic model . Thermodynamics $\cdot$ Regeneration

R. Bhaumik · N. K. Mondal ( $₫)$

Department of Environmental Science, The University

of Burdwan, Burdwan 713104, India

e-mail: nkmenvbu@gmail.com

\section{Introduction}

Fluorine is the most electronegative element and belongs to halogen group with atomic weight 19 and atomic number 9. It exists as a diatomic molecule with remarkably low dissociation energy $(38 \mathrm{kcal} / \mathrm{mol})$. Fluoride is a persistent and non-biodegradable pollutant that accumulates in soil, plants, wildlife and human beings (Tomar and Kumar 2013). In soil fluoride presents as earth crust (0.6-0.9\%) commonly associated with volcanic activity and gases. It is also present in water and air. However, in air not large quantities but an average concentration of fluoride $\left(0.5 \mu \mathrm{g} / \mathrm{m}^{3}\right)$ is found in the air (WHO 2004). Several fluoride-containing minerals such as topaz, fluorite, fluorapatite, cryolite, phosphorite, theorapatite, etc. are mainly responsible for fluoride contamination in groundwater and fluoride is also present in geochemical deposit which can be leached out by rainwater (Shahjee et al. 2013). Groundwater forms a major source of drinking water in urban as well as rural areas. According to previous researchers, excessive fluoride concentrations have been reported in groundwater in more than 20 developed and developing countries including India where 19 states are facing acute fluoride problems (Meenakshi and Maheshwari 2006). In West Bengal, major part of Birbhum, Bankura, Purulia,and part of Burdwan, are intensly affected by fluoride (Hernández-Montoyaa et al. 2012). Fluoride in drinking water is a pressing global issue as it can cause dental and skeletal fluorosis when present at levels above the World Health Organization (WHO 2008) drinking water guideline of $1.5 \mathrm{mg} / \mathrm{l}$.

The problems of excess fluoride in drinking water are aggravating day by day, as more surveys to assess the groundwater quality have been undertaken. So, it is very essential to bring down the fluoride levels to acceptable 
limits. Several methods have been suggested for removing excess fluoride from water: Nalgonda technology, activated alumina technology, coagulation and precipitation, ion exchange, electrodialysis, nanofiltration, reverse osmosis, etc. Among these methods, adsorption process is a surface phenomenon by which a multi-component fluid (gas or liquid) mixture is attracted to the surface of a solid adsorbent and forms attachments via physical or chemical bonds. Adsorption is recognized as the most efficient, promising and widely used fundamental approach in wastewater treatment processes (Foo and Hameed 2010).

Many natural adsorbent materials were tried in the past to find out efficient and economically viable defluoridating agents such as activated alumina (Ghorai and Pant 2005), alumina-gibbsite (Mariappan et al. 2003), activated carbon (Karthikeyan and Ilango 2007), calcite (Turner et al. 2010), clay (Coetzee et al. 2003), zeolite (Díaz-Nava et al. 2007), activated charcoal (Daifullah et al. 2007), bleaching earth (Mahramanlioglu et al. 2002), red mud (Tor et al. 2009), brick powder (Yadav et al. 2006), sugarcane charcoal (Mondal et al. 2013), waste tea ash (Mondal et al. 2012a) and rice husk ash (Mondal et al. 2012b).

Banana peel is a major waste found in tropical regions of India. There is no report on this waste regarding removal of fluoride. However, banana peel has been extensively used for removal of heavy metals such as $\mathrm{Pb}^{2+}, \mathrm{Cr}^{3+}, \mathrm{Co}^{2+}$ and $\mathrm{Ni}^{2+}$ (Abbasi et al. 2013; Memon et al. 2008; Annadurai et al. 2002). This prompted us to do research work in the adsorption of $F$ using banana peel dust. In this study the following objectives were undertaken: (1) to study the adsorption of $\mathrm{F}$ by modified banana peel dust, (2) to optimize the maximum adsorption of F using response surface methodology (3) to study the effect of various parameters on $\mathrm{F}$ adsorption and (4) use of various error analysis to check the adequacy of the isotherms and kinetic models.

In adsorption-based methods, it is desirable to have knowledge of the process variables and their influence on adsorption capacity to maximize the contaminant removal efficiency of the adsorbents (Singh et al. 2011). The conventional approach for optimization of process variables requires a very large number of experiments to be performed, which would be very expensive and time consuming. Recently, Singh et al. (2009) reported the linear (partial least squares) and non-liner (artificial neural networks) modelling approaches to predict the adsorption capacity of carbon for removal of phenol from aqueous solution. However, it requires a large number of batch experiments. To overcome this particular problem a statistical experimental design approach was introduced. Recently, several types of experimental methods have been employed in multivariate chemical process optimization (Roy et al. 2014; Chattoraj et al. 2014).

Among them, response surface modelling (RSM) is a widely used method for studying the effect of several variables influencing the responses by varying them simultaneously and carrying out a limited number of experiments. RSM consists of three major steps: performing statistically designed experiments, estimating the coefficients in a mathematical model and predicting the response and checking the adequacy of the model (Bhaumik et al. 2013).

\section{Materials and methods}

Preparation of banana peel dust

Banana peels (Musa paradisiaca) were collected from local fruit market, washed with tap water randomly and then washed with double-distilled water. These peels were sun dried for $12 \mathrm{~h}$ followed by drying at $50{ }^{\circ} \mathrm{C}$ for $24 \mathrm{~h}$. One-third of peels were cut and ground well using mortar and pestle, then sieved to obtain the desired size fractions $(250 \mu \mathrm{m})$ and named as adsorbent BPD-1. Another onethird dried peels were activated with $1 \% \mathrm{HCHO}$ solution and followed by dried in oven-maintained temperature range of $120-140{ }^{\circ} \mathrm{C}$ for a period of $12 \mathrm{~h}$. Then, the thermally activated modified peels were washed with distilled water until the $\mathrm{pH}$ was neutral, then dried in shed at room temperature and then the dried ash was ground and sieved to obtain $250 \mu \mathrm{m}$ particle size (Kumar et al. 2007) as adsorbent BPD-2.

For the synthesis of the activated Ca-impregnated adsorbent, BPD-2 was impregnated with a calcium solution extracted from egg shell (Hernández-Montoyaa et al. 2012). The extraction procedure comprises a digestion of $50 \mathrm{~g}$ of egg shells using 11 of acetic acid $(25 \%$, v/v). The resulting solution $(100 \%, \mathrm{v} / \mathrm{v})$ was rich in calcium $(12,604 \mathrm{mg} / \mathrm{l})$. An additional solution $(30 \%, \mathrm{v} / \mathrm{v})$ was prepared by dilution (1:4) of the previous one with deionized water. Typical impregnation ratio was $2 \mathrm{ml}$ of solution per gram of BPD-2.

The remaining part of peels was treated with $30 \% \mathrm{Ca}^{2+}$ solution extracted from eggshell followed by chemically activated peel materials, washed with double-distilled water until the $\mathrm{pH}$ was neutral and dried in shed at room temperature. Materials were well ground and sieved to obtain desired particle size $(250 \mu \mathrm{m})$ and named as adsorbent BPD-3 (Hernández-Montoyaa et al. 2012). Thus, prepared adsorbents were preserved within a plastic container and subjected to various physicochemical parameters and used for adsorption study. 


\section{Adsorption experiments}

Adsorption experiments were carried out by varying $\mathrm{pH}$, initial concentrations $(\mathrm{mg} / \mathrm{l})$, adsorbent dose $(\mathrm{g} / 100 \mathrm{ml})$, particle size $(\mu \mathrm{m})$, contact time $(\mathrm{min})$, stirring rate or agitation speed $(\mathrm{rpm})$ and temperature $(\mathrm{K})$. The influence of $\mathrm{pH}$ (2.0-10.0), adsorbent dose $(0.2-2.4 \mathrm{~g} / 100 \mathrm{ml})$, contact time $(20,40,60,80,120,180$ and $240 \mathrm{~min})$, initial fluoride concentration $(1.5,3.0,5.0,7.0,10.0$ and $20.0 \mathrm{mg} / \mathrm{l})$ and temperature $(303,313,323$ and $333 \mathrm{~K}$ ) were evaluated during the present study. The contents (adsorbent/100 ml solution) were kept for constant shaking for a duration of time in a temperature-controlled magnetic stirrer at $303 \pm 1 \mathrm{~K}$ and then the solids were separated through filtration using Whatman 42 filter paper and the volume was finally adjusted to $25 \mathrm{ml}$. Then solutions were collected for analysis and residual fluoride concentration was determined spectrophotometrically using Spectrophotometer (Perkin Elmer Landa 35). Analysis of fluoride was carried out by following SPANDS methods (APHA, AWWA 1998). Observation with a scanning electron microscope (SEM) was performed at the Centre of Scanning Electron Microscopy of Burdwan University on HITACHI-S-530 operating at an accelerating voltage of $20 \mathrm{kV}$. Infrared photograph was recorded by Fourier transform infrared spectroscopy (FTIR) (BRUKER, Tensor 27).

The point of zero change $\left(\mathrm{pH}_{\mathrm{ZPC}}\right)$ of the respective adsorbents was determined by the batch equilibrium method using $100 \mathrm{mg}$ of each adsorbent (BPD-1, BPD-2 and BPD-3) in $50 \mathrm{ml}$ of $0.05 \mathrm{M} \mathrm{KNO}_{3}$ deoxygenated aqueous solution. Blank without adsorbents were also run in the same initial $\mathrm{pH}$ values. After shaking for $24 \mathrm{~h}$ at $250 \mathrm{rpm}$ at room temperature, the final $\mathrm{pH}$ of solutions and blanks was measured. The $\mathrm{pH}_{\mathrm{ZPC}}$ was determined as the $\mathrm{pH}$ of $\mathrm{KNO}_{3}$ solution which did not change after contact with the samples.

Each experiment was conducted three times and average values reported. Control experiments, performed without addition of adsorbent, confirmed that the sorption of fluoride on the walls of Erlenmeyer flasks was negligible. The percentage removal of fluoride was obtained using the following equation:

$\%$ of fluoride removal $=\left(\frac{C_{\mathrm{i}}-C_{\mathrm{f}}}{C_{\mathrm{i}}}\right) \times 100$

The adsorption capacity of fluoride ions or amount of fluoride ions adsorbed $\left(q_{\mathrm{e}}\right)$ presented in milligram per gram was determined using the following mass balance equation:

$q_{\mathrm{e}}=\frac{\left(C_{\mathrm{i}}-C_{\mathrm{f}}\right) V}{m}$ where, $C_{\mathrm{i}}$ and $C_{\mathrm{f}}$ denoted the initial and equilibrium fluoride ion concentrations $(\mathrm{mg} / \mathrm{l})$, respectively. $V$ is the volume of the solution in litres (1) and $m$ is the mass of the adsorbent used (g).

The kinetic study was carried out at $\mathrm{pH} 6.0$ with initial fluoride concentration $(10 \mathrm{mg} / \mathrm{l})$ at $24 \mathrm{~h}$. The effect of $\mathrm{pH}$ on the defluoridation efficiency was investigated in a $\mathrm{pH}$ range of 2.0-10.0 at $0.5 \mathrm{~h}$. Adsorption equilibrium studies were conducted by varying the initial fluoride concentration over a range of $1.5-15.0 \mathrm{mg} / \mathrm{l}$ at $\mathrm{pH} 6.0 \pm 0.1$ during $0.5 \mathrm{~h}$. The effect of adsorbent dose for fluoride uptake capacity was studied in the range of $0.1-10.0 \mathrm{~g} / \mathrm{l}$. In order to investigate the regeneration efficiency of the studied adsorbents, regeneration experiments were performed with pH 2.0-14.0 and initial concentration $10.0 \mathrm{mg} / \mathrm{l}$.

\section{Response surface modelling}

Response surface modelling (RSM) is an empirical statistical technique that uses quantitative data obtained from appropriately designed experiments to determine regression model and operating conditions (Alam et al. 2007; Tan et al. 2008). The main objective of RSM is to determine the optimum set of operational variables of the process (Myers and Montgomery 2002).

The optimization involves estimation of the coefficients in a mathematical model and predicting the response and checking the adequacy of the model. The response model may be expressed as (Sahu et al. 2009):

$Y=f\left(X_{1}, X_{2}, X_{3}, \ldots \ldots \ldots . X_{n}\right) \pm e$,

where $Y$ is the response, $f$ is the response function, $X_{i}$ are the independent variables and $e$ is the experimental error. The form of response function, $f$, is unknown and may be very complicated. It largely depends on the nature of relationship between the response and the independent variables. RSM aims at approximating $f$ by a suitable polynomial in some region of the independent process variables. A higher-order polynomial, such as quadratic model may be expressed as (Can et al. 2006):

$Y=\beta_{0}+\sum_{i=1}^{n} \beta_{i} X_{i}+\sum_{i=1}^{n} \beta_{i i} X_{1}^{2}+\sum_{i=1}^{n} \sum_{j=1}^{n} \beta_{i j} X_{i} X_{j}+e$,

where $Y$ is the predicted response, $\beta_{0}$ the constant coefficient, $\beta_{i}$ the linear coefficients, $\beta_{i i}$ the quadratic coefficients, $\beta_{i j}$ the interaction coefficients, and $X_{i}, X_{j}$ are the coded values of the independent process variables and $e$ is the residual error.

The response surface modelling helps to investigate the response over the entire variables' space and to identify the region where it reaches its optimum value. 
Table 1 Physicochemical characteristics of BPD-1, BPD-2, BPD-3

\begin{tabular}{llll}
\hline Physical characteristics & BPD-1 & BPD-2 & BPD-3 \\
\hline $\mathrm{pH}$ & 5.6 & 6.1 & 7.2 \\
$\mathrm{EC}(\mathrm{mho} / \mathrm{cm})$ & 1.6 & 1.8 & 1.84 \\
Bulk density $\left(\mathrm{g} / \mathrm{cm}^{3}\right)$ & 0.75 & 0.64 & 0.88 \\
Particle density $\left(\mathrm{g} / \mathrm{cm}^{3}\right)$ & 2.1 & 2.5 & 2.8 \\
Porosity & 0.62 & 0.74 & 0.68 \\
Solubility in water $(\%)$ & 0.56 & 0.7 & 0.7 \\
Solubility in acid $(\%)$ & 0.4 & 0.62 & 0.77 \\
Moisture content $(\%)$ & 6.1 & 3.4 & 5.2 \\
Ash content $(\%)$ & - & 7.2 & - \\
BET surface area $\left(\mathrm{g} / \mathrm{cm}^{3}\right)$ & 312.3 & 884.7 & 912.3 \\
Particle size $(\mu \mathrm{m})$ & 250 & 250 & 250 \\
pH & 6.2 & 8.1 & 8.2 \\
\hline
\end{tabular}

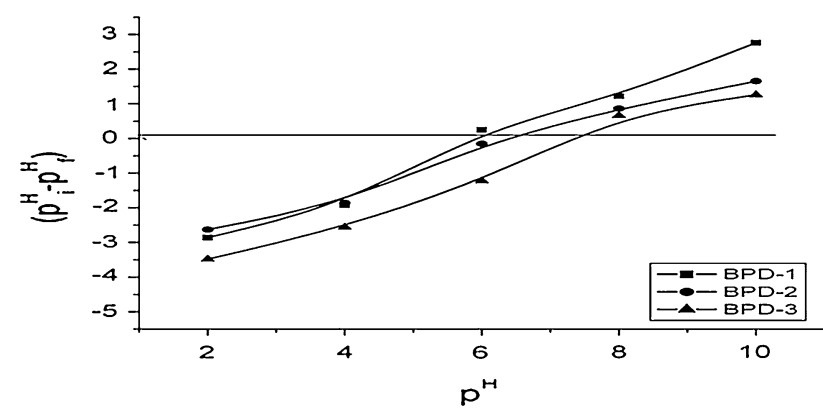

Fig. 1 Curve of zero-point charge curve of BPD-1, BPD-2 and BPD3 (experimental conditions: adsorbent dose: $1.5 \mathrm{~g} / 100 \mathrm{ml}$, temperature: $313 \mathrm{~K})$

\section{Results and discussions}

Characterization of banana peel dust (BPD)

Physicochemical characterisations of the adsorbents are shown in Table 1. From Table 1, comparing the important characteristics of BPD-1, BPD-2 and BPD-3, the carbon content of BPD-2 is found to be higher than others due to increasing in the ash content. BPD-2 and BPD-3 have the higher surface area and total pore volume than BPD-1, indicating the roughness of pore walls and increase of additional active sites which are responsible for adsorption of fluoride ions onto the surface of the BPD-3 and BPD-2 than BPD-1.

Determination of zero-point charge

Zero-point charge $\left(\mathrm{pH}_{\mathrm{ZPC}}\right)$ of BPD-1, BPD-2 and BPD-3 was measured by the solid addition method (Mondal 2010). Changes in final $\mathrm{pH}$ from initial $\mathrm{pH}$ indicate the adsorptive process through dissociation of functional groups as the active sites on the surface of adsorbents. Figure 1 and Table 1 show point of zero charge of BPD-1, BPD-2 and
BPD-3 6.2, 8.1 and 8.2, respectively. At low pH, the surface of the adsorbent is positive and reaction predominates and at higher $\mathrm{pH}$ the surface of adsorbent is negative. Here, the $\mathrm{pH}$ of the fluoride solution becomes lower than point charge, the association of fluoride ions with the adsorbent surface easily takes place and the surface of BPD- 3 is more effective than BPD-2 and BPD-1.

FTIR analysis

The FTIR spectra of BPD were obtained to understand the nature of the functional groups present in it. FTIR spectra (Fig. 2) displayed a number of peaks, indicating the complex nature of the adsorbent. Bands appearing at $3,905.88-3,258, \quad 2,928.13, \quad 2,856.01, \quad 1,734, \quad 1,631$, $1,393.45,1,269.11$ and $1,116.24-624.66 \mathrm{~cm}^{-1}$ in Fig. 2 were assigned to $-\mathrm{OH}$ stretching, $\mathrm{C}-\mathrm{H}$ stretching of alkane, $\mathrm{C}-\mathrm{H}$ and $\mathrm{C}=\mathrm{O}$ stretching of carboxylic acid or ester, $\mathrm{COO}-$ anion stretching, $\mathrm{OH}$ bending, $\mathrm{C}-\mathrm{O}$ stretching of ester or ether and $\mathrm{N}-\mathrm{H}$ deformation of amines, respectively. Out of these, carboxylic and hydroxyl groups played a major role in the removal of fluoride ions.

\section{SEM analysis}

Scanning electron microscopy (SEM) (Fig. 3a-c) helps to explain the surface structure of the powder consisting of the fine particles of irregular shape and size on external surface of BPD-1, BPD-2 and BPD-3. From Fig. 3a, b, it is seen that microporous structures of heterogeneous, rough surface with crater-like pores exist in banana peel and the particles are of irregular shape with their surface exhibiting a micro-rough texture, which can promote the adherence of fluoride. On the other hand, Fig. 3c shows little difference from Fig. 3a, b probably due to deposition of calcium of BPD.

\section{Effect of $\mathrm{pH}$}

As $\mathrm{pH}$ of the system controls the adsorption capacity through its influence on the surface properties of the adsorbent and species of adsorbate in solution, the effect of $\mathrm{pH}$ on adsorption of fluoride was studied in the $\mathrm{pH}$ range of 2.0-10.0 and results are depicted in Fig. 4a, b. The best adsorption and fluoride uptake capacity both occurred at $\mathrm{pH} 6.0$ (lower than $\mathrm{pH}_{\mathrm{ZPC}}$ ) and it is also shown that fluoride ions are more attached to the surace of BPD-3 due to having been chemically treated with $\mathrm{Ca}^{2+}$ solution (extracted from eggshell). The $\mathrm{pH}$ effect on fluoride removal is similar to what is observed for fluoride adsorption onto various adsorbents such as laterite (Gomoro et al. 2012), rice husk (Mondal et al. 2012b) and tea residue ash (Mondal et al. 2012a). Bearing in mind, that for 
Fig. 2 FTIR spectrum of banana peel dust (BPD)

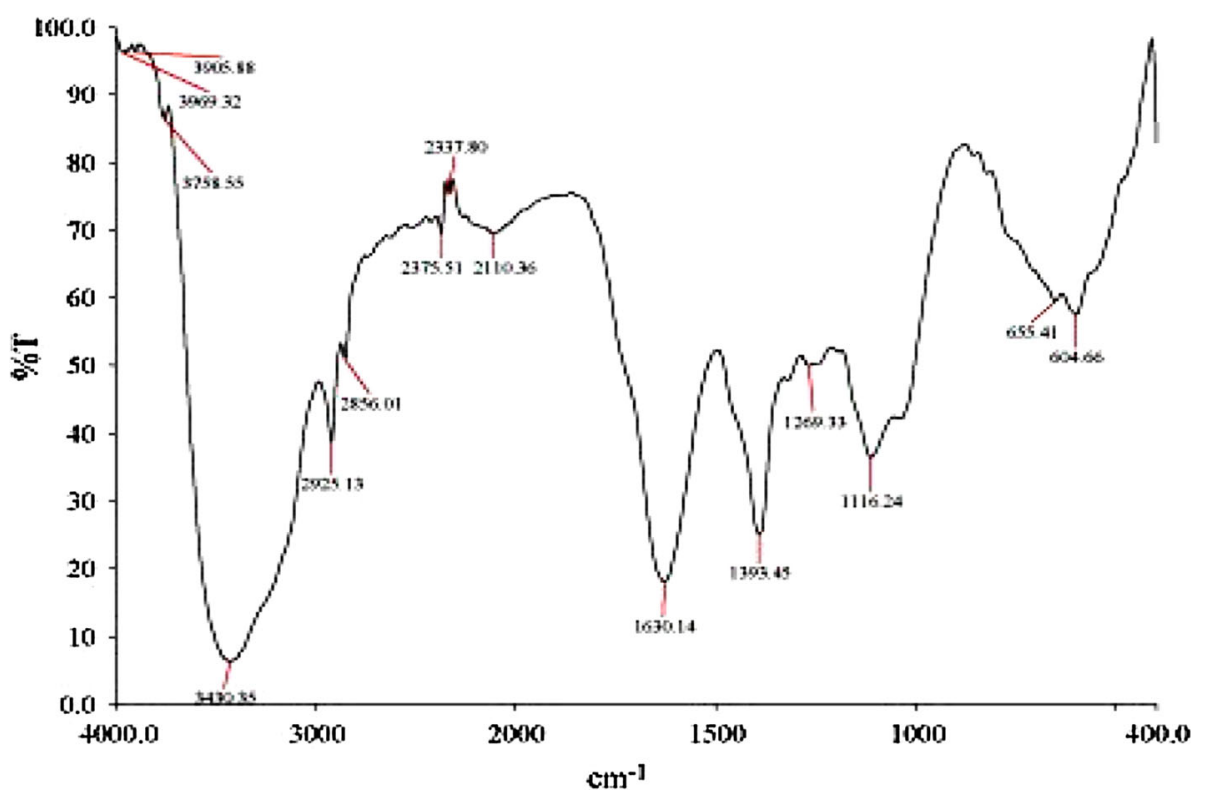

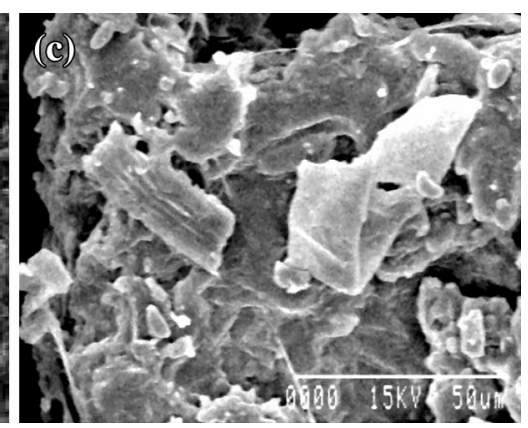

Fig. 3 a-c Scanning electron microscopy (SEM) images of BPD-1, BPD-2, BPD-3 before fluoride adsorption

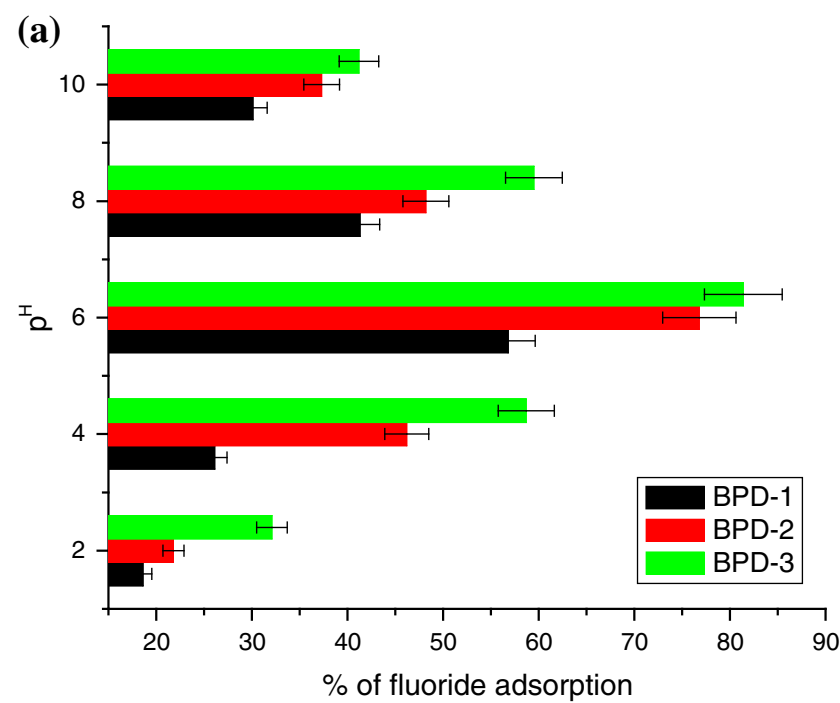

Fig. 4 a Effect of pH on \% of fluoride adsorption by BPD-1, BPD-2 and BPD-3 (experimental condition: initial fluoride concentration: $10 \mathrm{mg} / \mathrm{l}$, adsorbent dose: $0.05 \mathrm{~g} / \mathrm{l}$, contact time: $60 \mathrm{~min}$, agitation speed: $550 \mathrm{rpm}$, temperature: $313 \mathrm{~K}$ ). b Effect of $\mathrm{pH}$ on fluoride

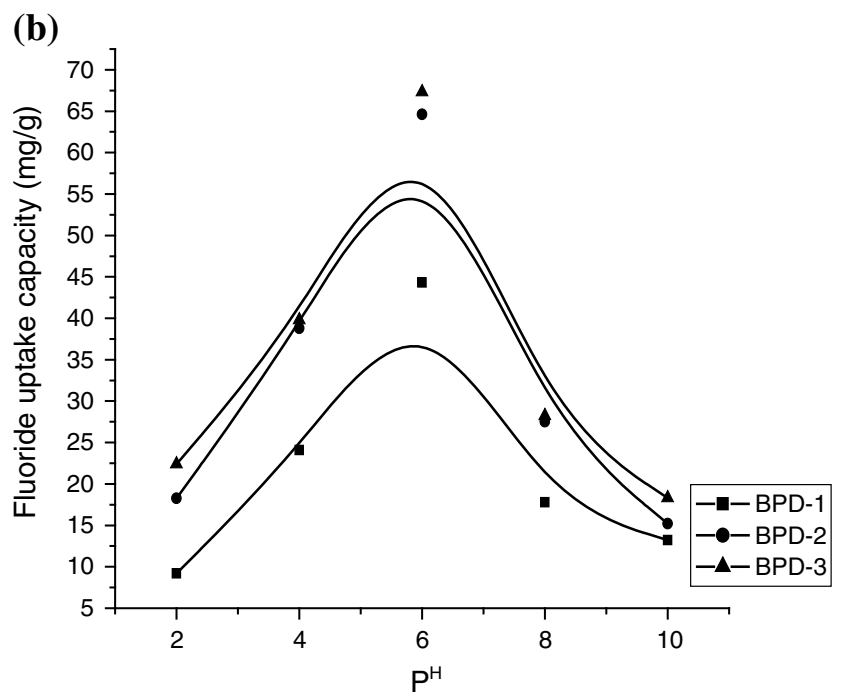

uptake capacity by BPD-1, BPD-2 and BPD-3 (experimental condition: initial fluoride concentration: $10 \mathrm{mg} / \mathrm{l}$, adsorbent dose: $0.05 \mathrm{~g} / \mathrm{l}$, contact time: $60 \mathrm{~min}$, agitation speed: $550 \mathrm{rpm}$, temperature: $313 \mathrm{~K}$ ) 

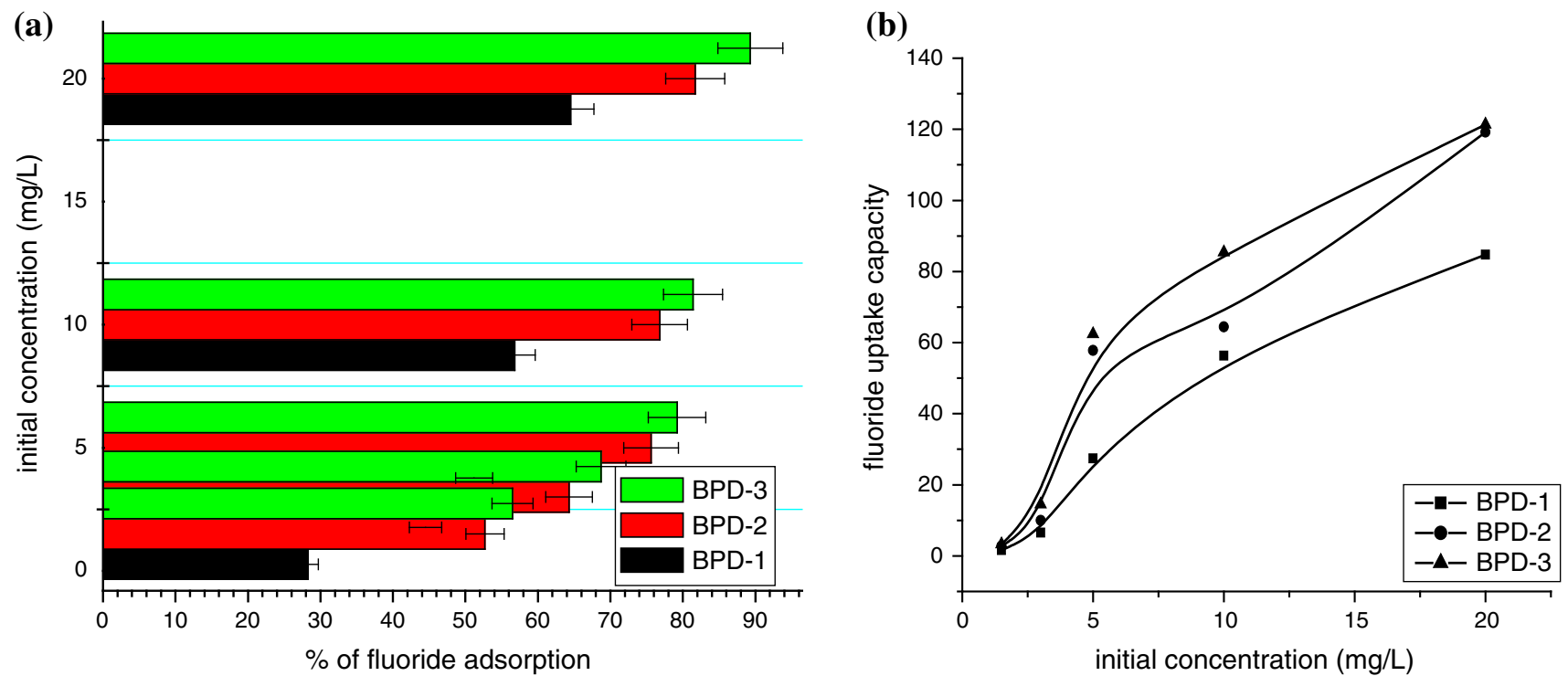

Fig. 5 a Effect of initial concentration $(\mathrm{mg} / \mathrm{l})$ on $\%$ of fluoride adsorption by BPD-1, BPD-2 and BPD-3 (experimental condition: $\mathrm{pH}$ : 6.0 , adsorbent dose: $0.05 \mathrm{~g} / \mathrm{l}$, contact time: $60 \mathrm{~min}$, agitation speed: $550 \mathrm{rpm}$, temperature: $313 \mathrm{~K}$ ). b Effect of initial concentration

$\mathrm{pH}<\mathrm{pH}_{\mathrm{ZPC}}(6.2-8.2)$, the $\mathrm{BPD}$ surface is positive, the high fluoride adsorption capacity found for $\mathrm{pH}<6.2$ is presumably due to the electrostatic attraction of fluoride by the positive surface of BPD (Tchomgui-Kamga et al. 2010).

The latter mechanism could also explain the fluoride adsorption capacity in a neutral medium (Eq. 3).

$$
\begin{aligned}
& \mathrm{M}-\mathrm{OH}+\mathrm{H}^{+}+\mathrm{F}^{-} \rightarrow \mathrm{M}-\mathrm{OH}_{2}^{+} \ldots \mathrm{F}^{-} \\
& \mathrm{M}-\mathrm{OH}+\mathrm{H}^{+}+\mathrm{F}^{-} \rightarrow \mathrm{M}^{+} \ldots \mathrm{F}^{-}+\mathrm{H}_{2} \mathrm{O} \\
& \mathrm{M}-\mathrm{OH}+\mathrm{F}^{-} \rightarrow \mathrm{M}^{+} \ldots \mathrm{F}^{-}+\mathrm{OH}^{-} \\
& \mathrm{M}-\mathrm{OH}+\mathrm{Na}^{+}+\mathrm{OH}^{-}+\mathrm{F}^{-} \\
& \quad \rightarrow \mathrm{M}-\mathrm{O}^{-} \ldots \mathrm{Na}^{+} \ldots \mathrm{F}^{-}+\mathrm{H}_{2} \mathrm{O}
\end{aligned}
$$

From Eq. (6), it is clear that the slight decrease in defluoridation capacity or a competition between hydride and fluoride with increasing $\mathrm{pH}$ from 6.0 to 8.0 is due to the decrease of surface positive change (Tchomgui-Kamga et al. 2010). A presumed fluoride adsorption mechanism is described by Eqs. (3)-(6) where $\mathrm{M}$ stands for calcium atom linked to the BPD. Under acidic condition, the surface of the adsorbent transformed to a positively charged one which facilitated the sorption of fluoride ions through anion exchange (Yadav et al. 2013).

\section{Effect of initial concentration}

The effect of initial fluoride concentration was investigated by adding fixed amount of adsorbents onto different fluoride concentration solutions $(1.5,3.0,5.0,10.0$ and (mg/l) on fluoride uptake capacity by BPD-1, BPD-2 and BPD-3 (experimental condition: $\mathrm{pH}$ : 6.0 , adsorbent dose: $0.05 \mathrm{~g} / 1$, contact time: $60 \mathrm{~min}$, agitation speed: $550 \mathrm{rpm}$, temperature: $313 \mathrm{~K}$ )

$15.0 \mathrm{mg} / \mathrm{l})$. The effect of initial fluoride concentration on the fluoride removal efficiency is illustrated in Fig. 5a, b. The results illustrated that fluoride removal efficiency decreased with increasing initial fluoride concentration and reached equilibrium at $10 \mathrm{mg} / \mathrm{l}$. The reason was that the capacity of the adsorbent materials gets exhausted sharply with the increase in initial fluoride concentration (Yadav et al. 2013). This is probably due to the fact that for a fixed adsorbent dose, the total available adsorption sites were limited, which became saturated at higher concentration. Similar trend has been reported for fluoride removal using neem charcoal (Chakrabarty and Sarma 2012); sugarcane charcoal (Mondal et al. 2013).

\section{Effects of adsorbent dose}

The effect of adsorbent doses was investigated on adsorption of fluoride by using BPD-1, BPD-2 and BPD-3 ranging from 0.01 to $1.0 \mathrm{~g} / \mathrm{l}$ dose (Fig. 6a, b). The percent adsorption of fluoride increases with an increase in the mass of adsorbent. Highest fluoride adsorptions are 69.4, 81.3 and $82.6 \%$ for BPD-1, BPD-2 and BPD-3, respectively, with initial fluoride concentration of $10 \mathrm{mg} / \mathrm{l}$. It has been observed that up to certain level, higher doses of adsorbent resulted in higher removal of fluoride. This is perhaps due to higher availability of surface and pore volume at higher doses (Yadav et al. 2013). However, due to aggregation among the available active binding sites may acts for less adsorption of fluoride at higher doses (Anwar et al. 2010). Also, due to lack of active binding 
(a)

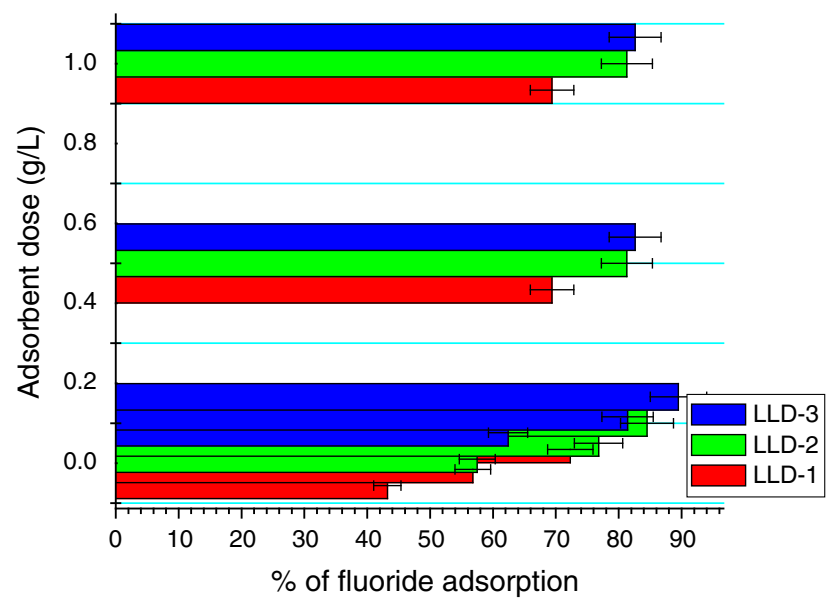

Fig. 6 a Effect of adsorbent dose (g/l) on \% of fluoride adsorption on fluoride adsorption by BPD-1, BPD-2 and BPD-3 (experimental condition: initial fluoride concentration: $10 \mathrm{mg} / \mathrm{l}, \mathrm{pH}$ : 6.0 , contact time: $60 \mathrm{~min}$, agitation speed: $550 \mathrm{rpm}$, temperature: $313 \mathrm{~K}$ ). b Effect

site, lower adsorption was obtained at low adsorbent doses (Karthikeyan et al. 2007).

\section{Effect of contact time}

The variation of fluoride adsorption were conducted by varying contact time (10-240 $\mathrm{min}$ ) with a dose of $0.1 \mathrm{~g} / \mathrm{l}$ at $313 \mathrm{~K}$ with $550 \mathrm{rpm}$ (Fig. 7a, b). The rate of fluoride adsorption was very rapid during the first $180 \mathrm{~min}$, and thereafter, the rate of fluoride adsorption remained constant. There was no significant increase in adsorption after about $180 \mathrm{~min}$. Initially, there were large number of vacant active binding sites in these three adsorbents (BPD-1, BPD-2 and BPD-3) and consequently large amounts of fluoride ions were bound rapidly onto the adsorbent. The binding site shortly became limited and the remaining vacant surface sites could not be occupied due to the formation of repulsive forces between the adsorbate on the solid surface and the liquid phase (Srivastava et al. 2006; Achak et al. 2009). Besides, the mesopores are saturated at the initial stage of adsorption where the fluoride ions are adsorbed. As a result, the driving force of mass transfer between liquid and solid phase in an aqueous adsorption system decreases with time elapse. Further, the fluoride ions have to pass through the deeper surface of the pores for binding and encounter much larger resistance which slows down the adsorption during the later phase of adsorption (Srivastava et al. 2006).

\section{Effect of agitation speed}

The effect of agitation speed on adsorption of fluoride ion was studied over the range of $250-850 \mathrm{rpm}$ for $3 \mathrm{~h}$

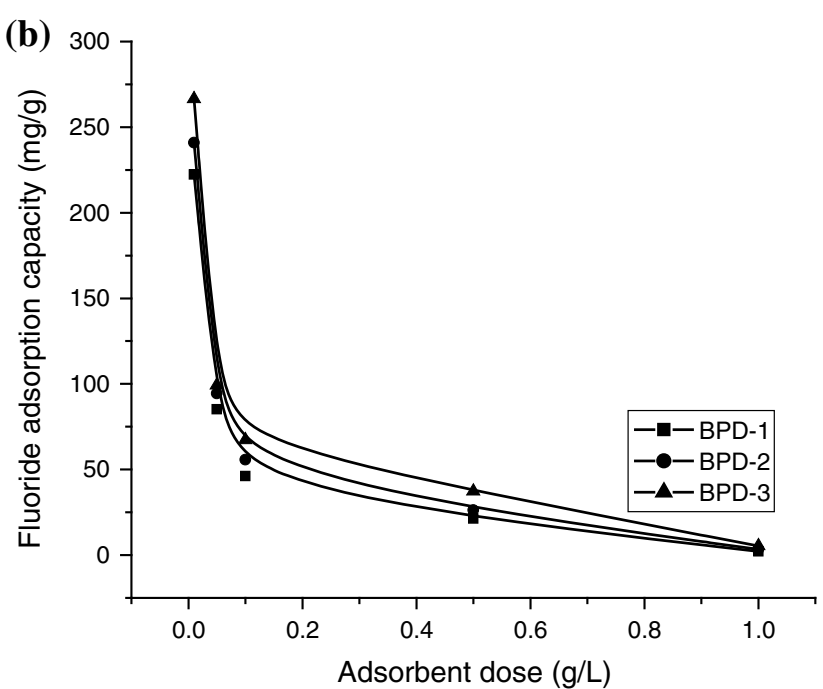

of adsorbent dose ( $\mathrm{g} / \mathrm{l})$ on fluoride uptake capacity by BPD-1, BPD-2 and BPD-3 (experimental condition: initial fluoride concentration: $10 \mathrm{mg} / \mathrm{l}, \mathrm{pH}$ : 6.0 , contact time: $60 \mathrm{~min}$, agitation speed: $550 \mathrm{rpm}$, temperature: $313 \mathrm{~K}$ )

with 11 water containing $10 \mathrm{mg} / \mathrm{l}$ fluoride ion concentration and $0.1 \mathrm{~g}$ of BPD-1, BPD-2 and BPD-3. Figure $8 \mathrm{a}, \mathrm{b}$ indicates that the percent adsorption increases with increasing of agitation speed and obtains a maximum $97.8 \%$ adsorption at near $650 \mathrm{rpm}$. At low speed, the fluoride ion adsorption rate (\%) and uptake capacity $(\mathrm{mg} / \mathrm{g})$ are lower than optimum because low speed could not spread the particles properly in the solution for providing active binding sites for adsorption of fluoride. The increase in both adsorption rate and uptake capacity at a higher agitation speed could be explained in terms of the reduction of boundary layer thickness around the adsorbent particles (Hanafiah et al. 2009) and a higher agitation speed also encourages a better mass transfer of fluoride ions from bulk solution to the surface of the adsorbent and shortens the adsorption equilibrium time (Hanafiah et al. 2009). Beyond $650 \mathrm{rpm}$ agitation speed, adsorption rate and uptake capacity of fluoride ions both remain constant due to getting equilibrium in condition. Almost similar observation was reported by the authors in their earlier study (Bhaumk et al. 2012).

\section{Effect of temperature}

The effect of temperature on fluoride removal was studied in the solution temperature range from 313 to $343 \mathrm{~K}$. It reveals that fluoride removal decreased with the increase in temperature for all the tested adsorbents. Figure $9 \mathrm{a}, \mathrm{b}$ shows reduction in both percentage of fluoride adsorption and adsorption capacity due to increase of temperature beyond $313-343 \mathrm{~K}$. This result suggests that low temperature favors the removal of 

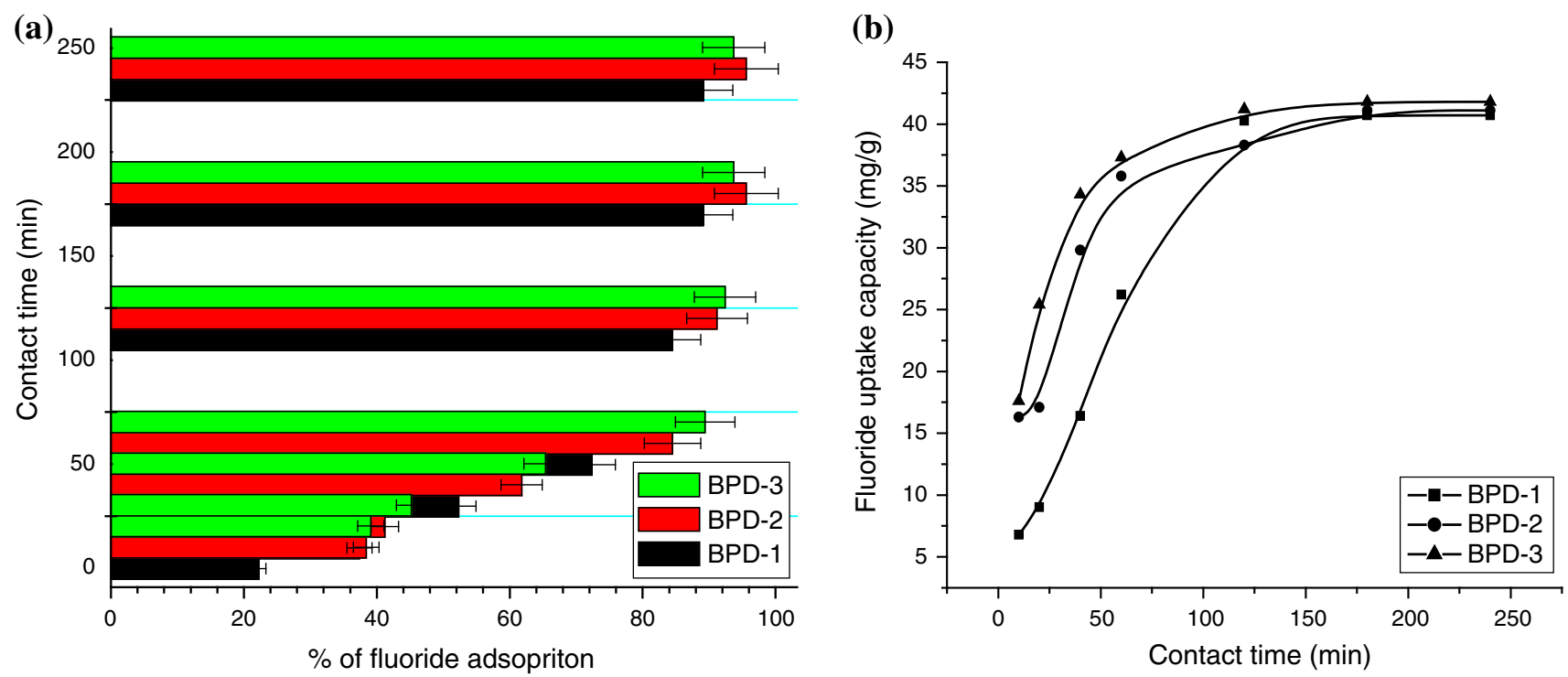

Fig. 7 a Effect of contact time on (minute) \% of fluoride adsorption by BPD-1, BPD-2 and BPD-3 (experimental condition: initial fluoride concentration: $10 \mathrm{mg} / \mathrm{l}, \mathrm{pH}: 6.0$, adsorbent dose: $0.1 \mathrm{~g} / \mathrm{l}$, agitation speed: $550 \mathrm{rpm}$, temperature: $313 \mathrm{~K}$ ). b Effect of contact time

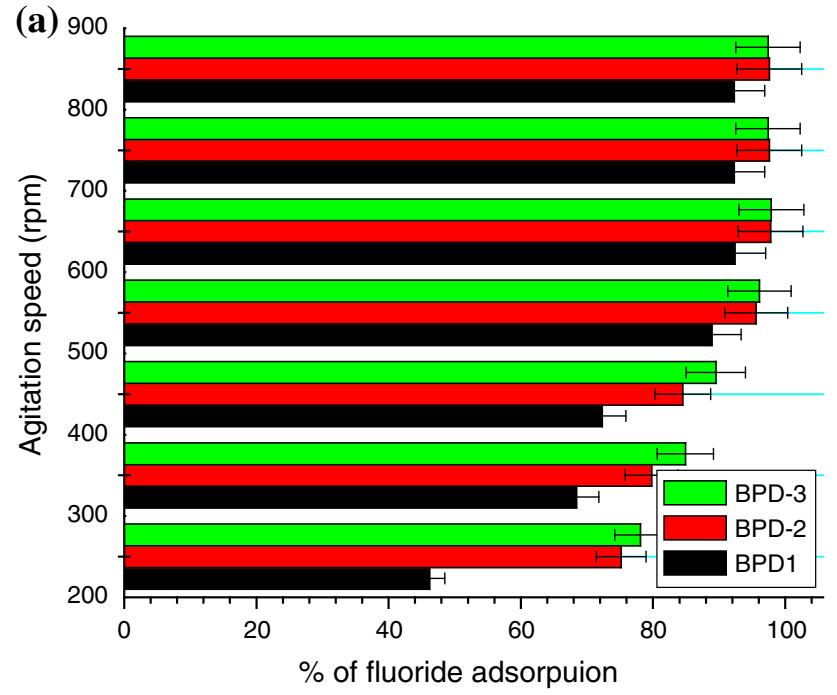

Fig. 8 a Effect of agitation speed (rpm) on \% on fluoride adsorption by BPD-1, BPD-2 and BPD-3 (experimental condition: initial fluoride concentration: $10 \mathrm{mg} / 1, \mathrm{pH}$ : 6.0 , adsorbent dose: $0.1 \mathrm{~g} / 1$, contact time: $60 \mathrm{~min}$, temperature: $313 \mathrm{~K}$ ). b Effect of agitation speed (rpm) on

fluoride molecules by adsorption on BPD-1, BPD-2 and BPD-3 as well as the adsorption process is exothermic in nature. The decreasing of removal rate may be due to that at high temperature the thickness of the boundary layer decreases due to increased tendency of the molecules to escape from the adsorbent surface to the solution phase, which results in a decrease in the adsorption capacity as temperature is increased (Sujana and Anand 2010). Similar results were previously reported by Sujana and Anand (2010).

(minute) on fluoride uptake capacity by BPD-1, BPD-2 and BPD-3 (experimental condition: initial fluoride concentration: $10 \mathrm{mg} / \mathrm{l}, \mathrm{pH}$ : 6.0, adsorbent dose: $0.1 \mathrm{~g} / \mathrm{l}$, agitation speed: $550 \mathrm{rpm}$, temperature: $313 \mathrm{~K})$

(b)

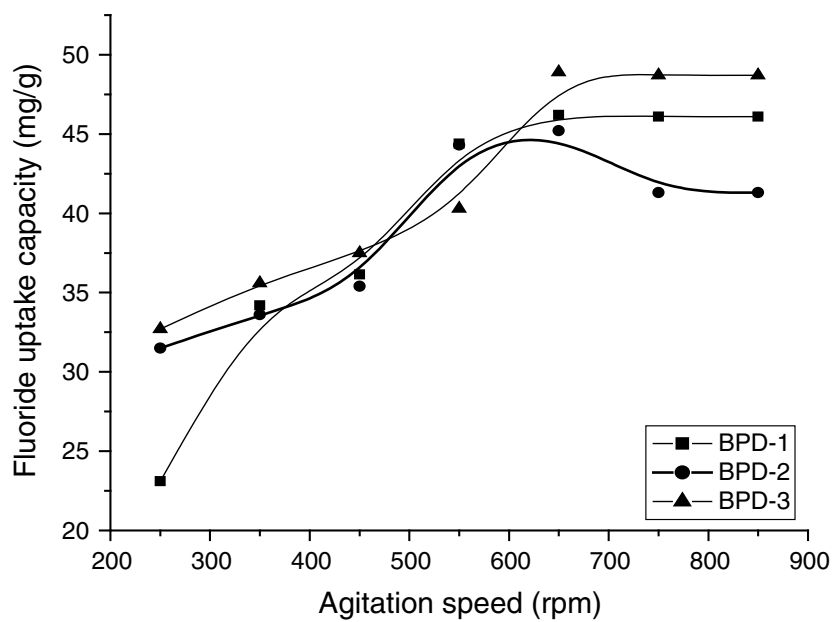

fluoride uptake capacity by BPD-1, BPD-2 and BPD-3 (experimental condition: initial fluoride concentration: $10 \mathrm{mg} / \mathrm{l}, \mathrm{pH}$ : 6.0 , adsorbent dose: $0.1 \mathrm{~g} / \mathrm{l}$, contact time: $60 \mathrm{~min}$, temperature: $313 \mathrm{~K}$ )

\section{Box-Behnken statistical analysis}

In this work, Box-Behnken design was used to evaluate the fluoride adsorption rate. The complete quadratic design model was composed of 17 experimental runs with three replicates at the centre points. Using analysis of variance (ANOVA), the significant of the model was justified also and the results were shown in Tables 2, 3 and 4 . The model $F$ value is the ratio of mean square for the individual term to the mean square for the residual. 
(a)

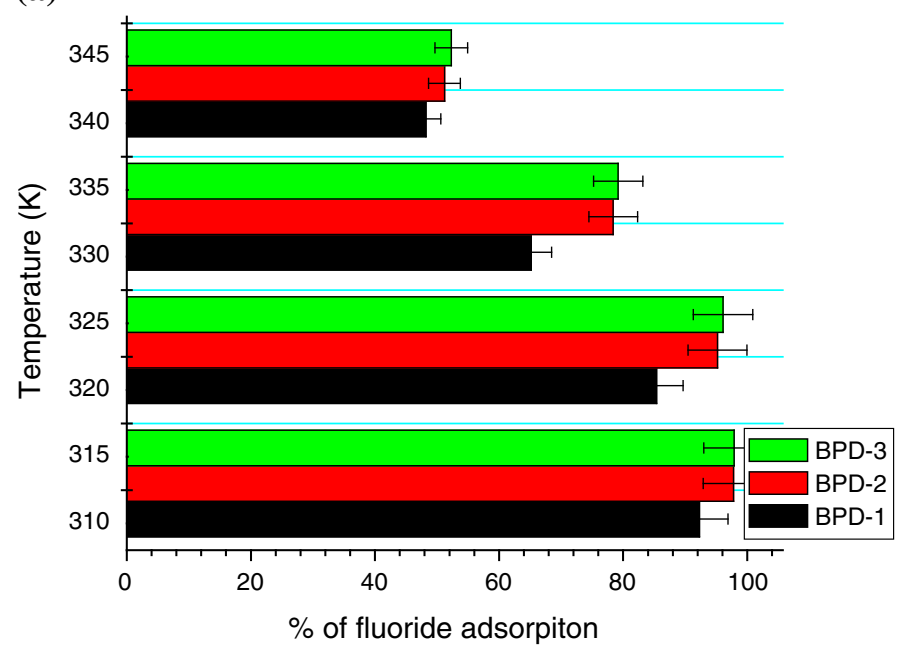

Fig. 9 a Effect of temperature $(\mathrm{K})$ on \% of fluoride adsorption by BPD-1, BPD-2 and BPD-3 (experimental condition: initial fluoride concentration: $10 \mathrm{mg} / \mathrm{l}, \mathrm{pH}$ : 6.0 , adsorbent dose: $0.1 \mathrm{~g} / \mathrm{l}$, contact time: $180 \mathrm{~min}$, agitation speed: $650 \mathrm{rpm})$. b Effect of temperature $(\mathrm{K})$ on

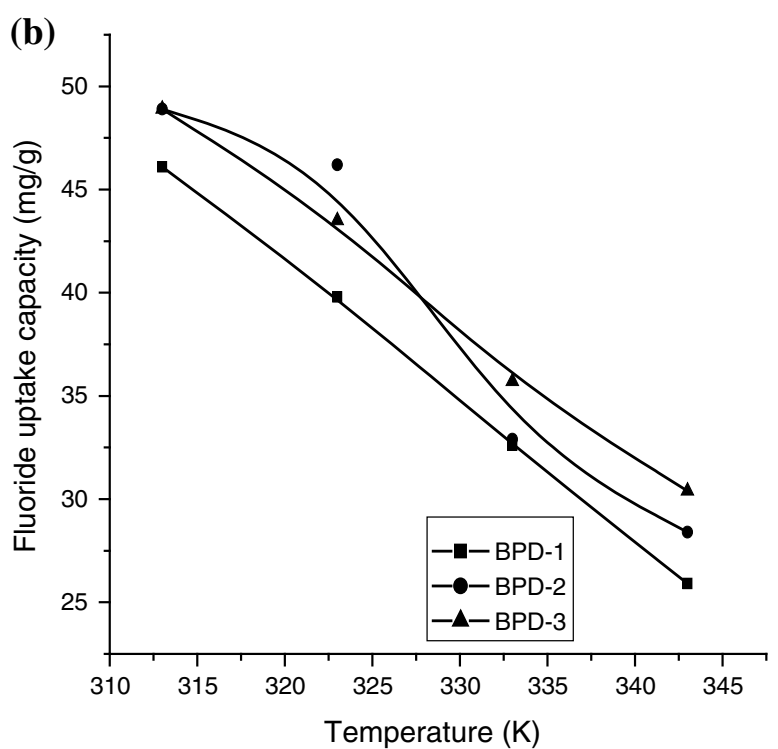

fluoride uptake capacity by BPD-1, BPD-2 and BPD-3 (experimental condition: initial fluoride concentration: $10 \mathrm{mg} / \mathrm{l}, \mathrm{pH}: 6.0$, adsorbent dose $0.1 \mathrm{~g} / \mathrm{l}$, contact time: $180 \mathrm{~min}$, agitation speed: $650 \mathrm{rpm}$ )

Table 2 Analysis of variance for fluoride adsorption rate onto BPD-1

\begin{tabular}{|c|c|c|c|c|c|}
\hline$P$ value source prob $>F$ & Sum of squares & $d f$ & Mean square & $F$ value & $P$ probability \\
\hline Model significant & $7,076.74$ & 9 & 786.30 & 70.09 & $<0.0001$ \\
\hline$A$-initial concentration & 914.16 & 1 & 914.16 & 81.49 & $<0.0001$ \\
\hline$B-\mathrm{pH}$ & 75.91 & 1 & 75.91 & 6.77 & 0.03 \\
\hline$C$-contact time & 649.88 & 1 & 649.88 & 57.93 & 0.0001 \\
\hline $\mathrm{AB}$ & 71.85 & 1 & 71.85 & 6.41 & 0.039 \\
\hline $\mathrm{AC}$ & 18.88 & 1 & 18.88 & 1.68 & 0.2857 \\
\hline $\mathrm{BC}$ & 190.44 & 1 & 190.44 & 16.98 & 0.0045 \\
\hline$A^{2}$ & 283.46 & 1 & 283.46 & 25.27 & 0.0015 \\
\hline$B^{2}$ & $3,359.78$ & 1 & $3,359.78$ & 299.49 & $<0.0001$ \\
\hline$C^{2}$ & 144.54 & 1 & 144.54 & 12.88 & 0.0089 \\
\hline Residual & 78.53 & 7 & 11.22 & & \\
\hline Lack of fit significant & 65.44 & 4 & 16.36 & 3.75 & 0.1531 \\
\hline Pure error & 1,309 & 3 & 4.36 & & \\
\hline Cor total & $7,155.26$ & 16 & & & \\
\hline SD & & 3.35 & & $R$-squared & 0.9890 \\
\hline Mean & & 69.18 & & Adj $R$-squared & 0.9749 \\
\hline C.V \% & & 4.84 & & Pred $R$-squared & 0.8428 \\
\hline PRESS & & $1,124.77$ & & Adeq precision & 24.394 \\
\hline
\end{tabular}

ANOVA for response surface Quadratic Model Analysis of variance table (Partial sum of square Type-III)

The Prob $>F$ value is the probability of $F$ statistics value and is used to test the null hypothesis. The parameters having an $F$-statistics probability value $<0.05$ are said to be significant. The $\mathrm{pH}$ of the solution, initial fluoride concentration, and contact time had a significant effect on fluoride adsorption. Once the optimization was over the experimental and model predicted values of the response variables were compared. The plot between experimental (actual) and predicted values of fluoride adsorption rate is shown in Fig. 10a-c. A good correlation between input and output variables is also shown by the model. 
Table 3 Analysis of variance for fluoride adsorption rate onto BPD-2

\begin{tabular}{|c|c|c|c|c|c|}
\hline$P$ value source prob $>F$ & Sum of squares & $d f$ & Mean square & $F$ value & $P$ probability \\
\hline Model significant & $7,580.92$ & 9 & 842.32 & 60.47 & $<0.0001$ \\
\hline$A$-initial concentration & $1,150.11$ & 1 & $1,150.11$ & 82.57 & $<0.0001$ \\
\hline$B-\mathrm{pH}$ & 68.39 & 1 & 68.39 & 4.91 & 0.0623 \\
\hline$C$-contact time & 346.88 & 1 & 346.88 & 24.90 & 0.0016 \\
\hline $\mathrm{AB}$ & 36.00 & 1 & 36.00 & 2.63 & 0.1491 \\
\hline $\mathrm{AC}$ & 102.31 & 1 & 102.31 & 7.35 & 0.0302 \\
\hline $\mathrm{BC}$ & 153.76 & 1 & 153.76 & 11.04 & 0.0127 \\
\hline$A^{2}$ & 423.57 & 1 & 423.57 & 30.41 & 0.0009 \\
\hline$B^{2}$ & $3,685.84$ & 1 & $3,685.84$ & 264.62 & $<0.0001$ \\
\hline$C^{2}$ & 118.70 & 1 & 118.70 & 8.52 & 0.0224 \\
\hline Residual & 97.50 & 7 & 13.93 & & \\
\hline Lack of fit significant & 76.89 & 4 & 19.22 & 2.80 & 0.2121 \\
\hline Pure error & 20.61 & 3 & 6.87 & & \\
\hline Cor total & 7678.42 & 16 & & & \\
\hline SD & & 3.73 & $R$-squared & & 0.9873 \\
\hline Mean & & 68.95 & Adj $R$-squared & & 0.9710 \\
\hline C.V. \% & & 5.41 & Pred $R$-squared & & 0.8550 \\
\hline PRESS & & 1113.34 & Adeq precision & & 22.561 \\
\hline
\end{tabular}

ANOVA for response surface Quadratic Model Analysis of variance table (Partial sum of square Type-III)

Table 4 Analysis of variance for fluoride adsorption rate onto BPD-3

\begin{tabular}{|c|c|c|c|c|c|}
\hline$P$ value source prob $>F$ & Sum of squares & $d f$ & Mean square & $F$ value & $P$ probability \\
\hline Model significant & $6,763.45$ & 9 & 751.49 & 124.24 & $<0.0001$ \\
\hline$A$-initial concentration & 793.30 & 1 & 793.30 & 131.15 & $<0.0001$ \\
\hline$B-\mathrm{pH}$ & 89.01 & 1 & 89.01 & 14.72 & 0.0064 \\
\hline$C$-contact time & 509.98 & 1 & 509.98 & 84.31 & $<0.0001$ \\
\hline $\mathrm{AB}$ & 94.61 & 1 & 94.61 & 15.64 & 0.0055 \\
\hline $\mathrm{AC}$ & 155.09 & 1 & 155.09 & 25.64 & 0.0015 \\
\hline $\mathrm{BC}$ & 56.25 & 1 & 56.25 & 9.30 & 0.0186 \\
\hline$A^{2}$ & 323.46 & 1 & 323.46 & 53.47 & 0.0002 \\
\hline$B^{2}$ & $3,178.47$ & 1 & $3,178.46$ & 525.47 & $<0.0001$ \\
\hline$C^{2}$ & 200.50 & 1 & 200.50 & 33.15 & 0.0007 \\
\hline Residual & 42.34 & 7 & 6.05 & & \\
\hline Lack of fit significant & 18.57 & 4 & 4.64 & 0.59 & 0.6973 \\
\hline Pure error & 23.77 & 3 & 7.92 & & \\
\hline Cor total & $6,805.80$ & 16 & & & \\
\hline SD & & 2.46 & $R$-squared & & 0.9938 \\
\hline Mean & & 71.47 & Adj $R$-squared & & 0.9858 \\
\hline C.V. \% & & 3.44 & Pred $R$-squared & & 0.9510 \\
\hline PRESS & & 333.31 & Adeq precision & & 32.320 \\
\hline
\end{tabular}

ANOVA for response surface Quadratic Model Analysis of variance table (Partial sum of square Type-III)

Effects of experimental parameters on fluoride adsorption

The effects of different experimental parameters such as solution $\mathrm{pH}$, initial fluoride concentration and contact time on the fluoride adsorption are shown in Figs. 11, 12 and 13. The fluoride adsorption capacity was increased with increase in initial fluoride concentration, contact time and decreased in solution $\mathrm{pH}$. The adsorption of fluoride favours comparatively at low $\mathrm{pH}$. Tables 2,3 and 4 show 
Fig. 10 The plot of predicted versus actual values for fluoride adsorption rate onto a BPD-1, b BPD-2, c BPD-3 (a)

Color points by value of \% Removal:

97.7

35.1

(b)

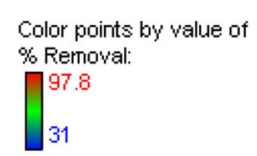

(c)

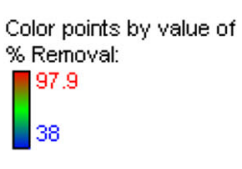

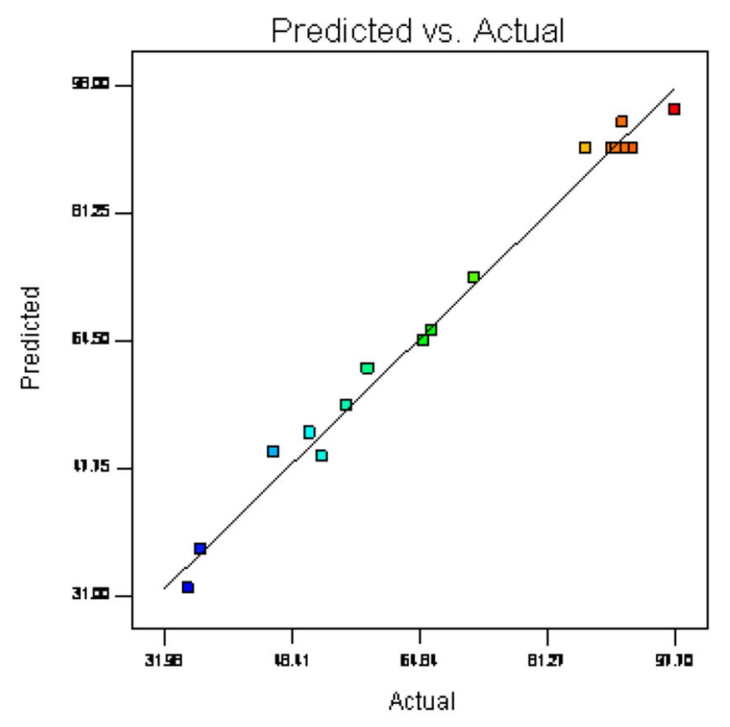
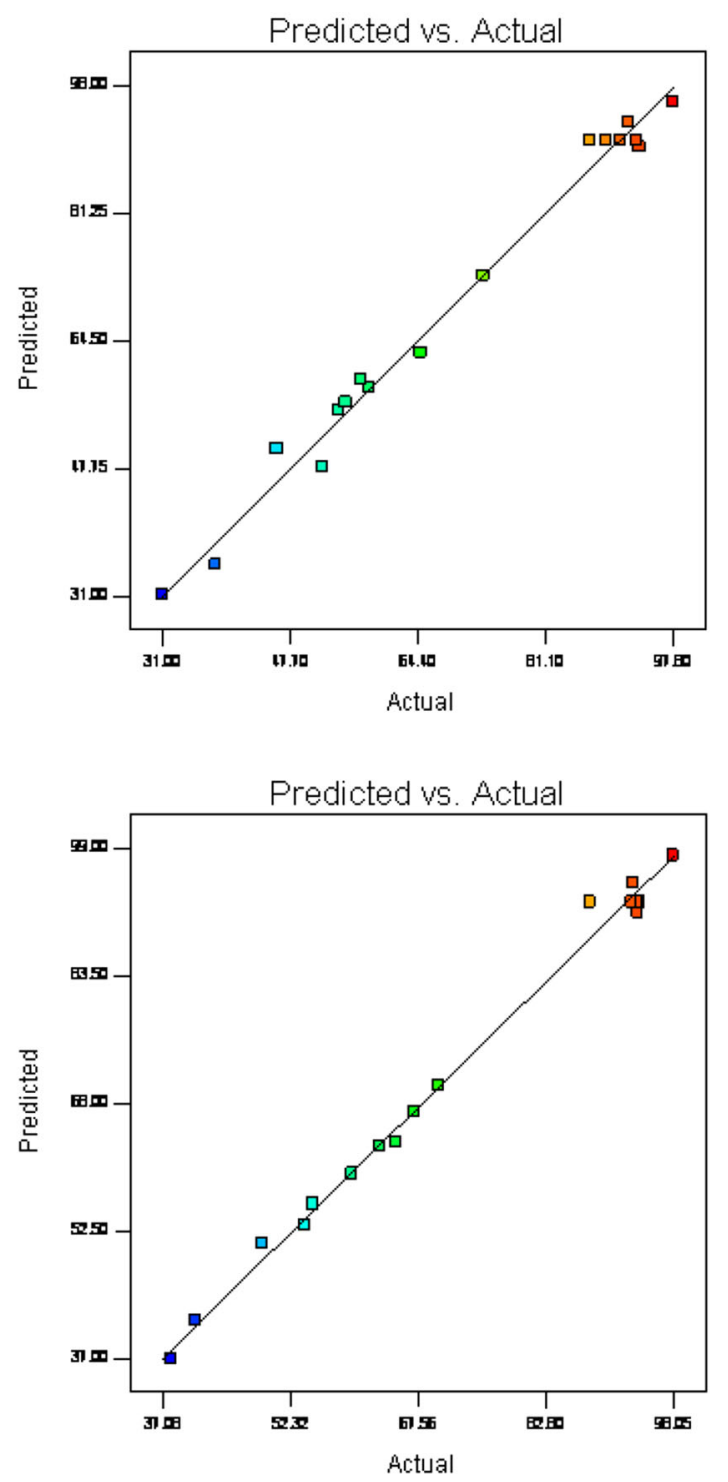
Fig. 11 The effects of different experimental parameters on the fluoride adsorption onto BPD-1: a $\mathrm{pH}$ and initial concentration,

b contact time and initial concentration, $\mathbf{c}$ contact time and $\mathrm{pH}$ (a)
$\%$ Removal
Design Points
97.7
35.1
X1 = A: initial concentration $\mathrm{X} 2=\mathrm{B}: \mathrm{pH}$
Actual Factor
C. contact time $=95.00$

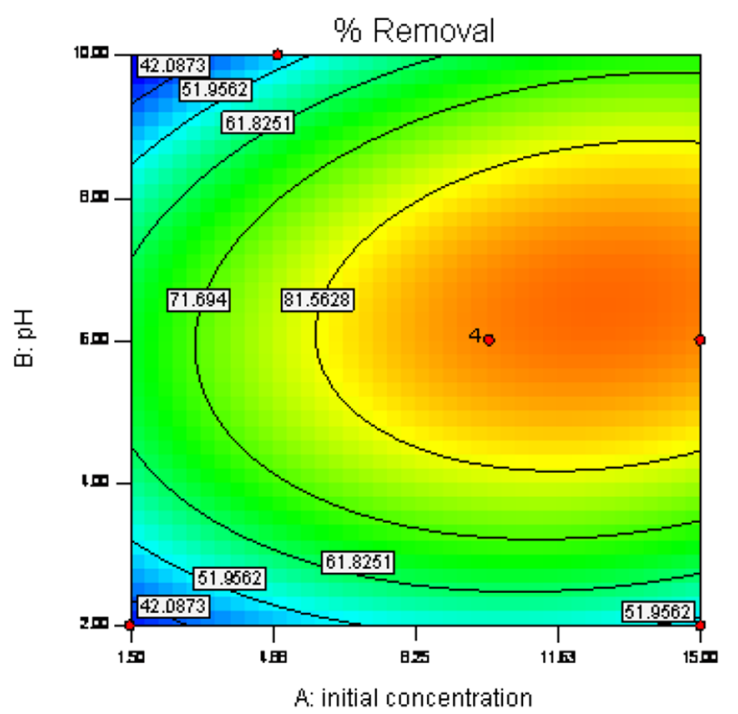

(b)

\% Rernoval
Design Points
$\prod^{97.7}$
35.1
$\mathrm{X} 1=\mathrm{A}:$ initial concentration
$\mathrm{X} 2=\mathrm{C}$ contact time
Actual Factor
B: $\mathrm{pH}=6.00$

(c)

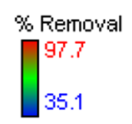

$\mathrm{X} 1=\mathrm{B}: \mathrm{pH}$

$\mathrm{X} 2=\mathrm{C}$ : contact time

Actual Factor

A: initial concentration $=8.25$

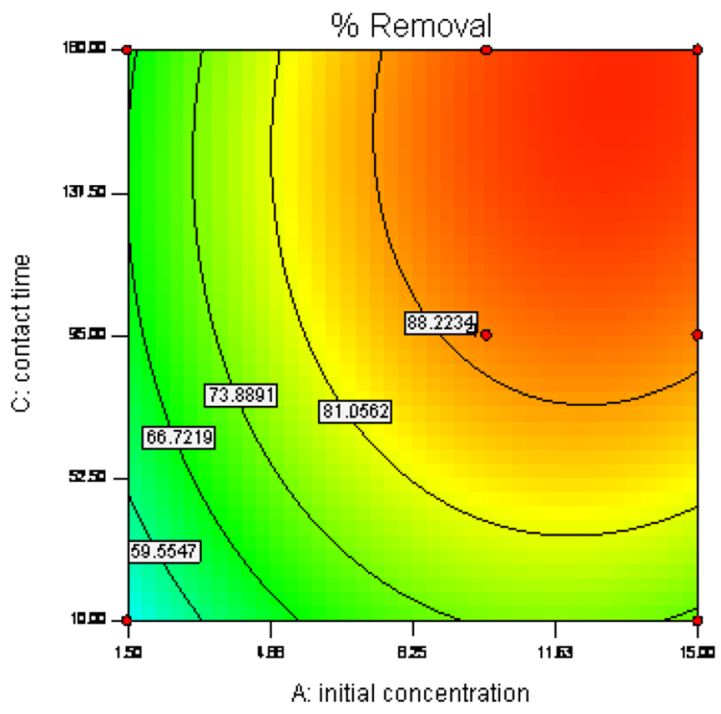


Fig. 12 The effects of different experimental parameters on the fluoride adsorption onto BPD-2: a $\mathrm{pH}$ and initial concentration,

b contact time and initial concentration, $\mathbf{c}$ contact time and $\mathrm{pH}$

\section{(a)}

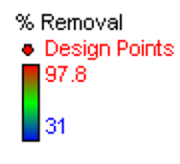

$\mathrm{X} 1=\mathrm{A}:$ initial concentration $\times 2=\mathrm{B}: \mathrm{pH}$

Actual Factor

C: contact time $=95.00$

(b)

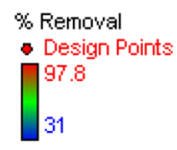

$\mathrm{X} 1=\mathrm{A}:$ initial concentration $\mathrm{X} 2=\mathrm{C}$. contact time

Actual Factor

$\mathrm{B}: \mathrm{pH}=6.00$

(c)

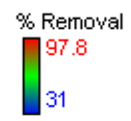

$\mathrm{X} 1=\mathrm{B}: \mathrm{pH}$

$\mathrm{X} 2=\mathrm{C}$ : contact time

Actual Factor

A: initial concentration $=8.25$
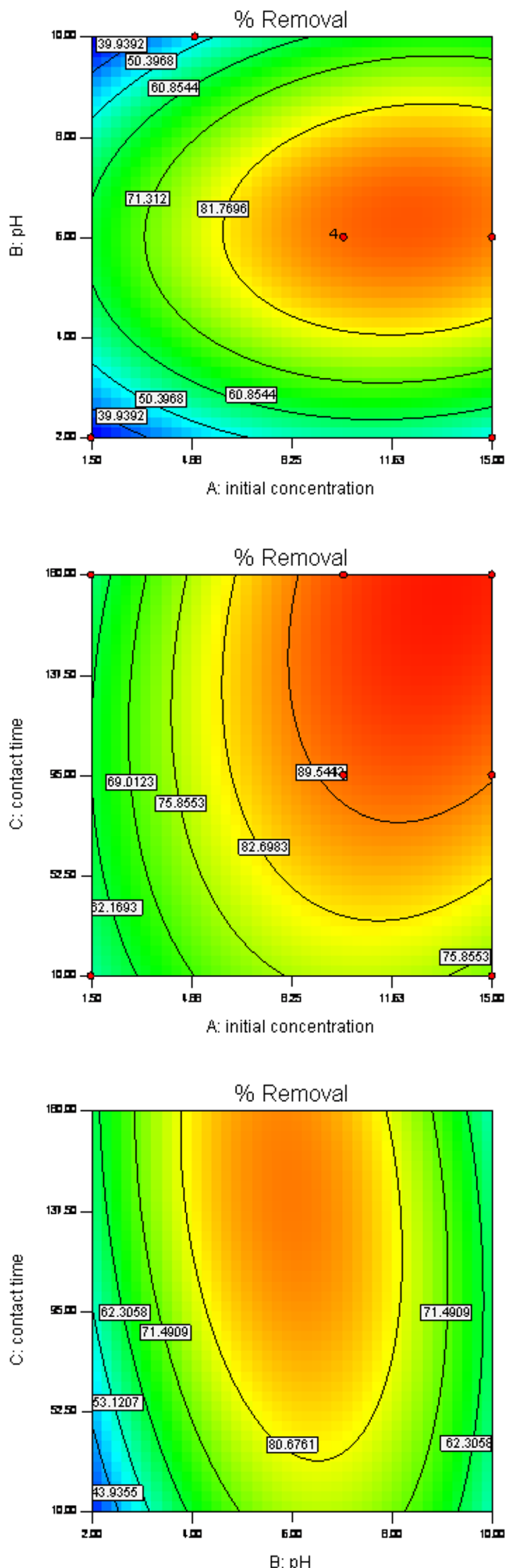
Fig. 13 The effects of different experimental parameters on the fluoride adsorption onto BPD-3: a $\mathrm{pH}$ and initial concentration,

b contact time and initial concentration, $\mathbf{c}$ contact time and $\mathrm{pH}$ (a)

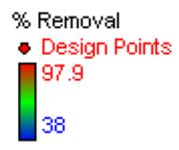

$\mathrm{X} 1=\mathrm{A}:$ initial concentration $\mathrm{X}_{2}=\mathrm{B}: \mathrm{pH}$

Actual Factor

C. contact time $=95.00$

(b)

\% Removal

- Design Points

97.9

38

$\mathrm{X} 1=\mathrm{A}:$ initial concentration $\mathrm{X} 2=\mathrm{C}$ : contact time

Actual Factor

$\mathrm{B}: \mathrm{pH}=6.00$

(c)

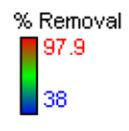

$\mathrm{X} 1=\mathrm{B}: \mathrm{pH}$

$\mathrm{X} 2=\mathrm{C}$ contact time

Actual Factor

A: initial concentration $=8.25$
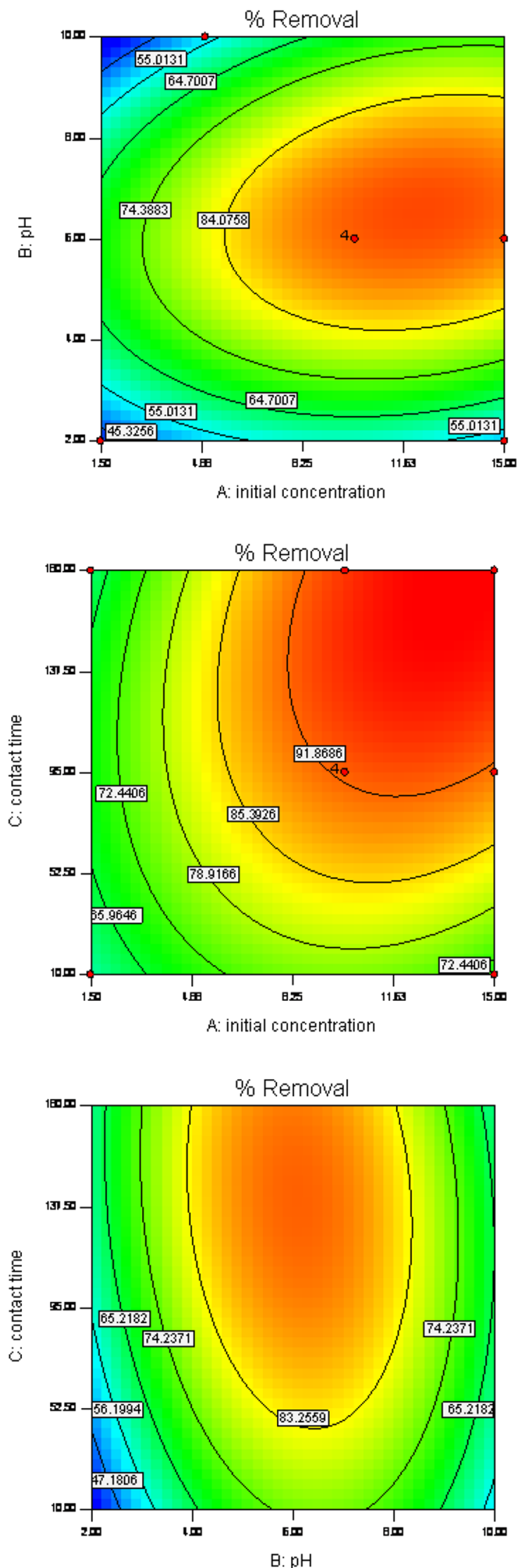
Table 5 The optimum values of the experimental parameters from desirability function

\begin{tabular}{lrcc}
\hline Parameters & BPD-1 & BPD-2 & BPD-3 \\
\hline $\mathrm{pH}$ & 6.31 & 6.05 & 6.78 \\
Contact time (min) & 167.17 & 175.45 & 153.14 \\
Initial concentration (mg/l) & 13.21 & 13.51 & 13.59 \\
\% of removal & 95.430 & 96.395 & 98.197 \\
\hline
\end{tabular}

the model $F$ value of BPD-1, BPD-2 and BPD-3 are 70.09, 60.47 and 124.24, respectively, which implies the model is significant. There is only $0.01 \%$ of chance that large "model $F$ value" could occur due to noise. The values of "prob $>F$ " $<0.05$ indicate model terms are significant, where values $>0.1$ indicate the model terms are not significant.

\section{Optimization of process variables}

The numerical optimization was applied to optimize the fluoride adsorption process and the optimum values of various parameters are provided in Table 5. Desirability values of $0.964,0.979$ and 1.0 were obtained after optimizing the process parameters for BPD-1, BPD-2 and BPD-3, respectively.

Isotherm study on fluoride adsorption

The adsorption isotherms pertaining to the fluoride ion on BPD were investigated. Four adsorption isotherms were used to fit the equilibrium data, namely Langmuir, Freundlich and D-R, Temkin. Its applicability is judged on the basis of goodness of fit. According to correlation coefficient $\left(R^{2}\right)$ adsorption of fluoride ions nicely fitted with Freundlich isotherm model.

The fluoride adsorption increased at lower concentration corresponds to each adsorbent (BPD-1, BPD-2 and BPD-3), whereas, at higher concentrations adsorption onto approached constant values. Suggesting typical Langmuir type of monolayer adsorption. Corresponds to each adsorbents (BPD-1, BPD-2 and BPD-3), suggesting typical Langmuir type of monolayer adsorption. Consequently the modelling of experimental data was carried out according to the Langmuir equation expressed by Eq. (7):

$\frac{1}{q_{\mathrm{e}}}=\frac{1}{K_{\mathrm{L}} q_{\mathrm{m}}} \frac{1}{C_{\mathrm{e}}}+\frac{1}{q_{\mathrm{m}}}$

The constants $q_{\mathrm{m}}$ and $K_{\mathrm{L}}$ can be determined from the slope of the liner plot of $C_{\mathrm{e}} / q_{\mathrm{e}}$ versus $C_{\mathrm{e}}$. The shape of the Langmuir isotherm can be used to predict whether a sorption system is favourable or unfavourable in a batch adsorption process. The essential features of the isotherm can be expressed in terms of a dimensionless constant, separation factor $\left(R_{\mathrm{L}}\right)$ that can be defined by the following relationship (Magdy and Daifullah 1998):

$R_{\mathrm{L}}=\frac{1}{1+K_{\mathrm{L}}+C_{\mathrm{i}}}$,

where $C_{\mathrm{i}}$ is the initial concentration $(\mathrm{mg} / \mathrm{l})$ and $K_{\mathrm{L}}$ is the Langmuir equilibrium constant $(1 / \mathrm{mg})$. The value of separation parameter $R_{\mathrm{L}}$ provides important information about the nature of adsorption. The value of $R_{\mathrm{L}}$ indicated the type of Langmuir isotherm to be irreversible $\left(R_{\mathrm{L}}=0\right)$, favourable $\left(0<R_{\mathrm{L}}<1\right)$, linear $\left(R_{\mathrm{L}}=1\right)$ or unfavourable $\left(R_{\mathrm{L}}>1\right)$. It can be explained apparently that when $K_{\mathrm{L}}>0$, sorption system is favourable (Chen et al. 2010).

The Freundlich parameters (Freundlich 1906) were obtained by fitting the experimental data to the linearised equation derived from Eq. (9):

$\log q_{\mathrm{e}}=\log K_{\mathrm{f}}+\frac{1}{n} \log C_{\mathrm{e}}$,

where $q_{\mathrm{e}}$ is the amount of solute per unit weight of adsorbent adsorbed at equilibrium $(\mathrm{mg} / \mathrm{g})$ and $K_{\mathrm{f}}$ is a constant for the system, related to the bonding energy.

$\mathrm{D}-\mathrm{R}$ isotherm model is widely used to determine the physical or chemical adsorption phenomenon and related to heterogeneity of energies over the surface (Stipp 1999). It can be expressed as

$q_{\mathrm{e}}=q_{\mathrm{DR}} \exp \left(-K_{\mathrm{DR}}^{\varepsilon^{2}}\right)$,

where $q_{\mathrm{e}}$ is the adsorption capacity at equilibrium condition, $q_{\mathrm{DR}}$ is the Dubinin-Radushkevich constant representing the theoretical maximum sorption capacity and $K_{\mathrm{DR}}$ is the constant of the adsorption energy which is related to mean adsorption energy $(E)$ where it is transferred to the surface of the solid from infinity in the solution. $\varepsilon$, the Polanyi potential is defined by

$\varepsilon=R T \ln \left(1+\frac{1}{C_{\mathrm{e}}}\right)$,

where $R$ is the gas constant $(8.314 \mathrm{~J} / \mathrm{mol} / \mathrm{K})$ and $T$ is the absolute temperature. Insert Eqs. (11) into (12) and take natural $\log$ of both sides gives:

$\ln q_{\mathrm{e}}=\ln q_{\mathrm{DR}}-K_{\mathrm{DR}} R^{2} T^{2} \ln \left(1+\frac{1}{C_{\mathrm{e}}}\right)$

It is apparent that the D-R isotherm equation would not be simplified to the Langmuir or Freundlich type of isotherm. Furthermore, plot of $\ln q_{\mathrm{e}}$ versus $\varepsilon^{2}$ should lead to a straight line, and its slope is given by

Slope $=-K_{\mathrm{DR}} R^{2} T^{2}$

$K_{\mathrm{DR}}$ can be correlated with $E$ as Choy et al. (1999), where the mean adsorption energy $(E)$ can be calculated as 
Table 6 Parameters of isotherm models on adsorption of fluoride by BPD-1, BPD-2 and BPD-3

\begin{tabular}{llll}
\hline Isotherm models & BPD-1 & BPD-2 & BPD-3 \\
\hline Langmuir & $K_{\mathrm{L}}=0.19$ & $K_{\mathrm{L}}=0.83$ & $K_{\mathrm{L}}=0.87$ \\
& $R_{\mathrm{L}}=0.83$ & $R_{\mathrm{L}}=0.75$ & $R_{\mathrm{L}}=0.82$ \\
& $q_{\mathrm{m}}=17.43$ & $q_{\mathrm{m}}=26.31$ & $q_{\mathrm{m}}=39.5$ \\
& $R^{2}=0.91$ & $R^{2}=0.99$ & $R^{2}=0.99$ \\
Freundlich & $K_{\mathrm{f}}=9.42$ & $K_{\mathrm{f}}=0.071$ & $K_{\mathrm{f}}=0.062$ \\
& $n=1.4$ & $n=5.1$ & $n=6.7$ \\
D-R & $R^{2}=0.98$ & $R^{2}=0.94$ & $R^{2}=0.99$ \\
& $q_{\max }=13.64$ & $q_{\mathrm{max}}=61.4$ & $q_{\mathrm{max}}=84.3$ \\
& $K_{\mathrm{DR}}=1.16$ & $K_{\mathrm{DR}}=0.12$ & $K_{\mathrm{DR}}=0.06$ \\
& $E_{\mathrm{S}}=0.65$ & $E_{\mathrm{S}}=2.04$ & $E_{\mathrm{S}}=2.89$ \\
Temkin & $R^{2}=0.93$ & $R^{2}=0.95$ & $R^{2}=0.99$ \\
& $B_{1}=2.6$ & $B_{1}=4.16$ & $B_{1}=3.16$ \\
& $A=0.78$ & $K_{\mathrm{T}}=5.71$ & $K_{\mathrm{T}}=6.2$ \\
& $R^{2}=0.87$ & $R^{2}=0.93$ & $R^{2}=0.94$ \\
\hline
\end{tabular}

$E=\frac{1}{\sqrt{2 K_{\mathrm{DR}}}}$

The D-R isotherm equation has been used to determine the mean adsorption energy $(E)$ that may provide useful information with regard to whether or not adsorption is subject to a chemical or physical process. The typical range of bonding energy for ion-exchange mechanisms is 8 and $16 \mathrm{~kJ} / \mathrm{mol}$, indicating that chemisorption may play a significant role in the sorption, while for values of $E<8 \mathrm{~kJ} /$ $\mathrm{mol}$, the adsorption process is of a physical in nature.

Temkin isotherm also represents the binding heterogeneity with a simple expression, which has predictive power over a wide range of concentrations (Johnson and Arnold 1995). Temkin isotherm can be expressed in linear form:

$q_{\mathrm{e}}=B_{\mathrm{T}} \ln K_{\mathrm{T}}+B_{\mathrm{T}} \ln C_{\mathrm{e}}$,

where $R$ is the gas constant $(8.314 \mathrm{~J} / \mathrm{mol} / \mathrm{K}), T$ the absolute temperature in Kelvin, $B_{\mathrm{T}}$ is the constant related to the heat of adsorption and $K_{\mathrm{T}}(1 / \mathrm{min})$ is the Temkin isotherm binding constant.

From the linear Eq. (7) of Langmuir isotherm for fluoride adsorption, the parameters were calculated along with regression coefficients shown in Table 6. Maximum adsorption capacity, $\left(q_{\mathrm{m}}\right)$, for complete monolayer coverage is found in Table $6 . K_{\mathrm{L}}(\mathrm{l} / \mathrm{g})$ is the adsorption constant related to the affinity of binding sites $(1 / \mathrm{g})$ and lower values of $K_{\mathrm{L}}(0.19,0.83$ and 0.87 for BPD-1, BPD-2 and BPD-3, respectively) indicate that the particle radius of adsorbent was small toward adsorption (Anwar et al. 2010). As the values of $R_{\mathrm{L}}$ below 1 for all the studied adsorbents, the overall adsorption process is favourable (Langmuir 1918).
From the linear Eq. (9) of Freundlich equation, fluoride adsorption and the parameters were calculated as shown in Table 6. The Freundlich isotherm model was found best fitted with experimental data as it possesses higher $R^{2}$ value (0.98, 0.94 and 0.99) for BPD-1, BPD-2 and BPD-3, respectively. $K_{\mathrm{F}}$ is a Freundlich constant that shows adsorption capacity on heterogeneous sites with non-uniform distribution of energy level and $n$ value shows the intensity between adsorbate and adsorbent (Table 6). The values of $n$ prove that the adsorption of fluoride ions onto BPD-1, BPD-2 and BPD-3 are favourable as the magnitude lies between 1 and 10 (Achak et al. 2009).

The maximum adsorption capacity $\left(q_{\mathrm{DR}}\right)$ obtained from D-R isotherm of BPD-1, BPD-2 and BPD-3 are 13.64, 61.4 and 84.33 , respectively, higher than the value of adsorption capacity obtained from Langmuir isotherm. D-R isotherm gives $K_{\mathrm{DR}}$ constant and idea about the mean free energy $E(\mathrm{~kJ} / \mathrm{mol})$ of adsorbate when it is transferred to the surface of the solid from infinity in the solution. The $E$ values of BPD-1, BPD-2 and BPD-3 are 0.65, 5.86 and 13.9, respectively, directing the physical adsorption mechanism of fluoride onto these adsorbents (Table 6).

Table 6 shows Temkin isotherm parameters, $B_{\mathrm{T}}$ related to heat of adsorption and Temkin isotherm constants $\left(K_{\mathrm{T}}\right.$, $1 / \mathrm{mg}$ ). The lower values of $B_{\mathrm{T}}<8$ (Table 6) indicate that the interaction between fluoride ions and BPD is weak and the adsorption process of fluoride ions can be expressed as physisorption.

Kinetic study in adsorption of fluoride

The effect of contact time on the adsorption of fluoride by BPD was studied for initial concentration $0.1 \mathrm{~g} / \mathrm{l}$. The contact time varied from 10 to $240 \mathrm{~min}$ (Fig. 7a). It was observed that most of the adsorption occurs within $3 \mathrm{~h}$ of contact time. Thereafter, the rate of removal became slow. The adsorption capacity increased from 6.8 to $40.7,16.3$ to $41.1,17.6$ to $41.8 \mathrm{mg} / \mathrm{g}$ in case of BPD-1, BPD-2 and BPD-3, respectively, with increasing time from 10 to 180 min.

The pseudo-first-order, pseudo-second-order and intraparticle diffusion kinetic models were used to investigate the adsorption kinetics of fluoride and to quantify the extent of uptake in the adsorption process. Simple pseudofirst-order kinetic model (Lagergren 1898), pseudo-secondorder model (Ho et al. 2002) and intra-particle diffusion model (Weber and Morris 1963) are represented by the following Eqs. (16-19):

Pseudo-first-order

$\log \left(q_{\mathrm{e}}-q_{\mathrm{t}}\right)=\log q_{\mathrm{e}}-\frac{k_{1} t}{2.303}$ 
Pseudo-second-order

$\frac{t}{q_{\mathrm{t}}}=\frac{1}{k_{2} q_{\mathrm{e}}^{2}}+\frac{1}{q_{\mathrm{e}}} t$

The initial adsorption rate $h(\mathrm{mg} / \mathrm{g} / \mathrm{min})$ is defined as

$h=k_{2} q_{\mathrm{e}}^{2}$

The intra-particle diffusion

$q_{\mathrm{e}}=k_{\mathrm{id}} t^{0.5}+C$

where $k_{\text {id }}$ is the intraparticle (pore) diffusion rate constant $\left(\mathrm{mg} / \mathrm{g} / \mathrm{min}^{0.5}\right)$ and $C$ is the intercept that gives an idea about the thickness of the boundary layer. The larger the value of $C$ the greater the boundary-layer effect. When the external transport of the adsorbate is greater than internal transport, then the adsorption rate is governed by intraparticle diffusion.

Kinetic studies are significant for any kind of biosorption processes. Adsorption kinetics not only describes the adsorption mechanism of fluoride ions on adsorbents but also describes the fluoride ion adsorption rate which controls the contact time of fluoride ions at the solid-liquid interface (Ho et al. 2000). From Table 7, it is observed that pseudo-second-order kinetics shows good correlation for fluoride removal for all used types of BPD. The values of second-order rate constant are calculated as 0.05, 0.009 and $0.008 \mathrm{mg} / \mathrm{g} / \mathrm{min}$ for BPD-1, BPD-2 and BPD-3, respectively. However, pseudo-first-order and intraparticle diffusion plots have poor coefficient of correlation (Table 7). The adsorption mechanism depends on the physical and chemical characteristics of adsorbent and adsorbate, $\mathrm{pH}$ of medium, temperature, contact time and aids and mass transport process (Achak et al. 2009). The data were fitted with different kinetics equation, namely pseudo-first-order, pseudo-second-order and intraparticle diffusion kinetics models. Table 7 shows the values of pseudo-first-order, pseudo-second-order and intraparticle diffusion model constants. Comparing these models, according to regression coefficient $\left(R^{2}\right)$ the fluoride adsorption is well fitted to the pseudo-second order kinetic model and the adsorption rate $(\mathrm{mg} / \mathrm{g} / \mathrm{min}, h)$ was calculated as shown in Table 7 . The value of $h$ is high in BPD-3, BPD-2 and BPD-1, respectively, which indicates BPD-3 is more effective than others in fluoride adsorption.

\section{Thermodynamic parameters}

In order to study the feasibility of the process using BPD for fluoride removal, thermodynamic parameter free energy change $\left(\Delta G^{\circ}\right)$ of the process was calculated from the equilibrium constant value $\left(K_{\mathrm{a}}\right)$ using following the equations:
Table 7 Parameters of kinetic models on adsorption of fluoride by BPD-1, BPD-2 and BPD-3

\begin{tabular}{llll}
\hline Kinetic models & BPD-1 & BPD-2 & BPD-3 \\
\hline Pseudo-first-order & $q_{\mathrm{e} 1}=1.6$ & $q_{\mathrm{e} 1}=3.21$ & $q_{\mathrm{e} 1}=3.14$ \\
& $K_{\mathrm{ad} 1}=0.007$ & $K_{\mathrm{ad} 1}=0.009$ & $K_{\mathrm{ad} 1}=0.012$ \\
& $R^{2}=0.28$ & $R^{2}=0.34$ & $R^{2}=0.48$ \\
Pseudo-second-order & $q_{\mathrm{e} 2}=37.6$ & $q_{\mathrm{e} 2}=55.5$ & $q_{\mathrm{e} 2}=58.9$ \\
& $K_{\mathrm{ad} 2}=0.05$ & $K_{\mathrm{ad} 2}=0.009$ & $K_{\mathrm{ad} 2}=0.008$ \\
Intra-particle & $R^{2}=0.95$ & $R^{2}=0.99$ & $R^{2}=0.99$ \\
diffusion & $K_{\mathrm{it}}=1.06$ & $K_{\mathrm{it}}=1.30$ & $K_{\mathrm{it}}=0.91$ \\
& $I=5.07$ & $I=8.62$ & $I=9.92$ \\
& $R^{2}=0.87$ & $R^{2}=0.89$ & $R^{2}=0.89$ \\
\hline
\end{tabular}

Table 8 Thermodynamic parameters on adsorption of fluoride by BPD-1, BPD-2 and BPD-3

\begin{tabular}{lllll}
\hline $\begin{array}{l}\text { Thermodynamic } \\
\text { parameters }\end{array}$ & $\begin{array}{l}\text { Temperature } \\
(\mathrm{K})\end{array}$ & BPD-1 & BPD-2 & BPD-3 \\
\hline$\Delta G^{\circ}$ & 313 & -7.724 & -9.24 & -9.51 \\
& 323 & -5.23 & -7.15 & -7.61 \\
& 333 & -2.24 & -5.06 & -5.81 \\
& 343 & -0.72 & -0.297 & -0.97 \\
$\Delta H^{\circ}$ & & -62.33 & -72.57 & -83.21 \\
$\Delta S^{\circ}$ & & -0.26 & -0.209 & -0.24 \\
\hline
\end{tabular}

$k_{\mathrm{c}}=C_{\mathrm{Ae}} / C_{\mathrm{e}}$

$\Delta G^{\circ}=-R T \ln k_{\mathrm{c}}$

$\ln k_{\mathrm{c}}=-\Delta H^{\circ} / R T+\Delta S^{\circ} / R$,

where $K_{\mathrm{a}}$ is the equilibrium constant, $C_{\mathrm{ae}}$ and $C_{\mathrm{e}}$ indicate the equilibrium solute concentration $(\mathrm{mg} / \mathrm{l})$ on BPD and in solution, respectively, $R$ is the universal gas constant ( $\mathrm{J} / \mathrm{mole}$ ) and $T$ is the temperature in Kelvin. The Van't Hoff plot of $\ln k_{\mathrm{c}}$ against $1 / T$ (not shown) was used to find out the parameters. The negative value of $\Delta G^{\circ}$ decreased with increasing temperature from 313 to $343 \mathrm{~K}$, suggesting the adsorption process is unfavourable and non-spontaneous at higher temperature (Table 8). The negative value of $\Delta H^{\circ}$ and $\Delta \mathrm{S}^{\circ}$ for all three types of BPD indicates no structural changes and supports the physical adsorption on BPD surface after fluoride adsorption (Sujana and Anand 2010; Erdem et al. 2004).

Error analysis for isotherm studies

In the single component isotherm studies, the optimization procedure requires an error function to be defined to be able to evaluate the fit of the isotherm to the experimental equilibrium data. In this study, five different error functions (SAE, SSE, MPSD, $c^{2}$ and HYBRID) were examined, and 
in each case, the isotherm parameters were determined by minimizing the respective error function across the concentration range studied.

The sum of the squares of the errors (SSE) method (Rengaraj et al. 2007) is the most common error function in use. This error function can be represented by the following equation:

$\mathrm{SSE}=\sum_{i=1}^{p}\left(q_{\mathrm{e}, \mathrm{cal}}-q_{\mathrm{e}, \text { meas }}\right)_{i}^{2}$,

where, $q_{\mathrm{e}, \mathrm{cal}}$ and $q_{\mathrm{e}, \mathrm{meas}}$ are, respectively, the calculated and the measured value of the equilibrium adsorbate solid concentration in the solid phase $(\mathrm{mg} / \mathrm{g})$, and $p$ is the number of the data point.

Sum of the absolute error (SAE) is similar to the sum of the squares of the errors, and isotherm parameters determined using this error function would provide a better fit as the magnitude of the error increased, biasing the fit toward the high concentration data (Rengaraj et al. 2007):

$S A E=\sum_{i=1}^{p}\left|q_{\mathrm{e}, \mathrm{cal}}-q_{\mathrm{e}, \text { meas }}\right|_{i}$,

where $q_{\mathrm{e}, \mathrm{cal}}$ and $q_{\mathrm{e}, \text { meas }}$ are, respectively, the calculated and the measured value of the equilibrium adsorbate solid concentration in the solid phase $(\mathrm{mg} / \mathrm{g})$, and $p$ is the number of the data point.

Marquardt's Percent Standard Deviation (MPSD) error function was used previously by a number of researchers in the field (Rengaraj et al. 2007) and it is similar in some respects to a geometric mean error distribution modified according to the number of degrees of freedom of the system:

$\operatorname{MPSD}=100 \sqrt{\frac{1}{n-p} \sum_{i=1}^{p}\left(\frac{\left(q_{\mathrm{e}, \text { meas }}-q_{\mathrm{e}, \mathrm{cal}}\right)^{2}}{q_{\mathrm{e}, \text { meas }}}\right)}$,

where $q_{\mathrm{e}, \mathrm{estm}}$ and $q_{\mathrm{e}, \mathrm{exp}}$ are, respectively, the estimated and the experimental value of the equilibrium adsorbate solid concentration in the solid phase $(\mathrm{mg} / \mathrm{g}), n$ is number of isotherm parameters and $p$ is the number of the data point.

The Chi square test measures the difference between the experimental and model data (Boparai et al. 2011). The mathematical form of this test statistic can be expressed as

$\chi^{2}=\sum \frac{\left(q_{\mathrm{e}, \mathrm{exp}}-q_{\mathrm{e}, \mathrm{cal}}\right)^{2}}{q_{\mathrm{e}, \mathrm{cal}}}$,

where $q_{\mathrm{e}, \exp }$ is experimental equilibrium capacity data and $q_{\mathrm{e}, \mathrm{cal}}$ is the equilibrium capacity from a model. If data from the model are similar to experimental data, $\chi^{2}$ will be small and if they differ, $\chi^{2}$ will be large.

Hybrid Fractional Error Function (HYBRID) error function was developed by $\mathrm{Ng}$ et al. (2002) to improve the
Table 9 Error analysis of isotherm models on adsorption of fluoride by BPD-1

\begin{tabular}{llllll}
\hline Isotherm models & \multicolumn{5}{l}{ Error functions } \\
\cline { 2 - 6 } & SAE & SSE & MPSD & $\chi^{2}$ & HYBRID \\
\hline Freundlich & 0.99 & 0.98 & 0.08 & 0.16 & 0.05 \\
Langmuir & 1.0 & 1.0 & 0.06 & 0.12 & 0.03 \\
Temkin & 3.71 & 13.8 & 0.92 & 8.5 & 7.38 \\
D-R & 1.54 & 2.37 & 0.24 & 0.33 & 0.09 \\
\hline
\end{tabular}

Table 10 Error analysis of isotherm models on adsorption of fluoride by BPD-2

\begin{tabular}{llllll}
\hline Isotherm models & \multicolumn{5}{l}{ Error functions } \\
\cline { 2 - 6 } & SAE & SSE & MPSD & $\chi^{2}$ & HYBRID \\
\hline Freundlich & 0.91 & 0.82 & 0.01 & 0.05 & 1.9 \\
Langmuir & 0.52 & 0.28 & 0.07 & 0.02 & 0.99 \\
Temkin & 9.42 & 88.73 & 14.69 & 3.76 & 28.4 \\
D-R & 2.58 & 6.65 & 1.10 & 0.39 & 15.6 \\
\hline
\end{tabular}

fit of the sum of the squares of the errors at low concentrations by dividing it by the measured value. It also includes the number of degrees of freedom of the systems the number of data points, $n$, minus the number of parameters, $p$, of the isotherm equations as a divisor:

HYBRID $=\frac{100}{n-p} \sum_{i=1}^{n}\left[\frac{\left(q_{\mathrm{e}, \text { meas }}-q_{\mathrm{e}, \mathrm{cal}}\right)^{2}}{q_{\mathrm{e}, \text { meas }}}\right]_{i}$

The results for the error analyses are shown in Tables 9, 10 and 11 for Freundlich, Langmuir, D-R and Temkin isotherms in case of BPD-1, BPD-2 and BPD-3, respectively. Results of error analysis show the adsorption of fluoride on BPD-1, BPD-2 and BPD-3 all are more significant to Langmuir isotherm than other isotherm models due to lower value of each error functions. These data are used in the design of commercial adsorbers, and consequently, the more accurate the isotherm parameters, the more accurate are the system designs.

Regeneration study

After saturation the adsorbent surface no longer adsorbs fluoride ions from solution. Therefore, it is immensely important to regenerate the saturated adsorbent to overcome the disposal problem. Desorption of fluoride was studied using distilled water of different $\mathrm{pH}$ values ranging from 2 to 14. Initially, leaching of fluoride was found to be at $\mathrm{pH}$ 8.0 and maximum $88.06 \%$ desorption was achieved at $\mathrm{pH}$ 12.0 for BPD-3. But other two adsorbents (BPD-1 and BPD2) showed 76.0 and $80.0 \%$ desorption at $\mathrm{pH} 8.0$ and 10.0, 
Table 11 Error analysis of isotherm models on adsorption of fluoride by BPD-3

\begin{tabular}{llrrll}
\hline Isotherm models & \multicolumn{5}{l}{ Error functions } \\
\cline { 2 - 6 } & SAE & \multicolumn{1}{c}{ SSE } & MPSD & $\chi^{2}$ & HYBRID \\
\hline Freundlich & 1.8 & 3.24 & 0.37 & 0.17 & 6.4 \\
Langmuir & 0.27 & 0.07 & 0.92 & 0.004 & 0.14 \\
Temkin & 4.27 & 18.23 & 15.46 & 0.04 & 40.53 \\
D-R & 2.39 & 5.71 & 8.14 & 0.39 & 11.23 \\
\hline
\end{tabular}

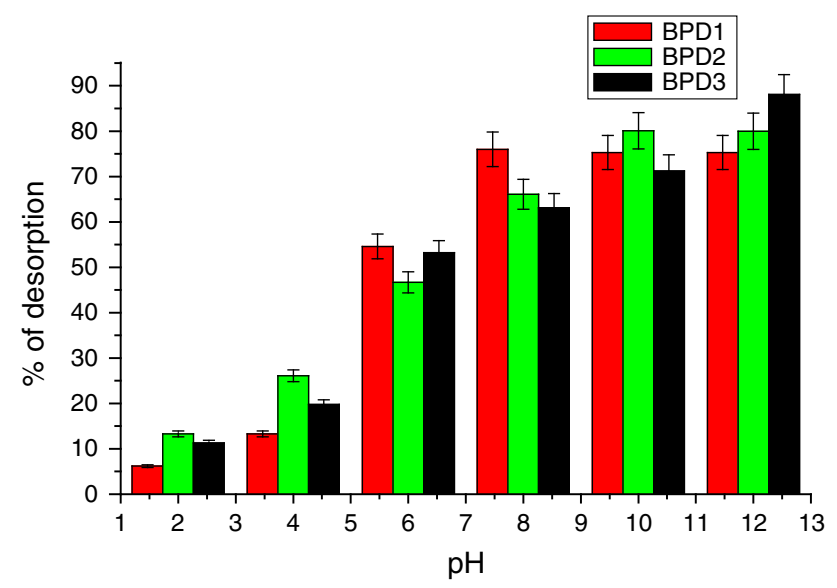

Fig. 14 Regeneration of adsorbents (BPD-1, BPD-2 and BPD-3) at different $\mathrm{pH}$

respectively (Fig. 14). Similar desorption of fluoride from calcareous soil was reported by Mondal et al. (2012c).

\section{Conclusion}

This work investigated the adsorption of fluoride onto banana peel dust. Experiments were made as a function of different adsorption parameters ( $\mathrm{pH}$, concentration, adsorbent dose, contact time, agitation speed and temperature). The surface characteristics make it suitable for sorptive defluoridation. $\mathrm{pH}$, electrical conductance, $\mathrm{pH}_{\mathrm{ZPC}}$, moisture content, bulk density, particle density, porosity, solubility in water and in acid, BET surface area and particle size, carbon content, etc. were examined to show the nature of surface of the different forms of banana peel dust (BPD-1, BPD-2 and BPD-3). BPD-3 and BPD-2 have the higher surface area and total pore volume than BPD-1 indicating the roughness of pore walls and increasing of additional active sites which are responsible for adsorption of fluoride ions onto the surface of the BPD-3 and BPD-2 than BPD-1. The points of zero charge of BPD-1, BPD-2 and BPD-3 are $6.2,8.1$ and 8.2 , respectively. Response surface methodology by the Box-Behnken model was used to examine the role of four process factors on fluoride removal. It was shown that a second-order polynomial regression model could properly interpret the experimental data with coefficient of determination $\left(R^{2}\right)$ value of $0.9890,0.9873$ and 0.9938 with $F$ value of $70.09,60.47$ and 124.24 for BPD-1, BPD-2 and BPD-3, respectively. The simultaneous optimization of the multi-response system by desirability function indicated that $95.43,96.39$ and $98.19 \%$ removal of fluoride is possible using BPD-1, BPD-2 and BPD-3, respectively. The Langmuir isotherm described the experimental results better than other isotherm models and showed maximum fluoride adsorption capacity $q_{\mathrm{m}}(\mathrm{mg} / \mathrm{g})$ 17.43, 26.31, 39.5 in case of BPD-1, BPD-2 and BPD-3, respectively. In this study, the magnitude of $\mathrm{E}$ is less than $8 \mathrm{~kJ} / \mathrm{mol}$ in three adsorbents which indicates the adsorption mechanism of fluoride was physisorption. From the error analysis it is clear that all the studied adsorbents nicely fitted with Langmuir isotherm model than other irother models. Adsorption process was observed to follow a pseudo-second-order kinetic model due to greater value of correlation coefficient $\left(R^{2}\right.$ values are $0.95,0.99$ and 0.99 in BPD-1, BPD-2 and BPD-3, respectively). Thermodynamic study suggests that adsorption of fluoride is favourable at lower temperature.

Acknowledgments The authors are grateful to Dr. Aloke Ghosh, Reader, Department of Chemistry, Burdwan University, Burdwan, West Bengal, India, for recording FTIR data and they also extend their gratitude to Dr. Srikanta Chakraborty, Incharge of SEM, USIC, University of Burdwan, West Bengal, India, for SEM study.

Open Access This article is distributed under the terms of the Creative Commons Attribution License which permits any use, distribution, and reproduction in any medium, provided the original author(s) and the source are credited.

\section{References}

Abbasi Z, Alikarami M, Nezhad ER, Moradi F, Moradi V (2013) Adsorptive removal of $\mathrm{Co}^{2+}$ and $\mathrm{Ni}^{2+}$ by peels of banana from aqueous solution. Univer J Chem 1(3):90-95

Achak M, Hafidi A, Ouazzani N, Sayadic S, Mandi L (2009) Low cost biosorbent banana peel for the removal of phenolic compounds from olive mill wastewater: kinetic and equilibrium studies. J Hazard Mater 166:117-125

Alam ZM, Muyibi SA, Toramae J (2007) Statistical optimization of adsorption processes for removal of 2,4-dichlorophenol by activated carbon derived from oil palm empty fruit bunches. J Environ Sci 6:674-677

Annadurai G, Juang RS, Lee DJ (2002) Adsorption of heavy metals from water using banana and orange peels. Water Sci Technol 47(1):185-190

Anwar J, Shafique U, Zaman W, Salman M, Dar A, Anwar S (2010) Removal of $\mathrm{Pb}(\mathrm{II})$ and $\mathrm{Cd}(\mathrm{II})$ from water by adsorption on peels of banana. Biores Technol 101:1752-1755

Bhaumik R, Mondal NK, Chattoraj S, Datta JK (2013) Application of response surface methodology for optimization of fluoride removal mechanism by newly developed biomaterial. Am J Anal Chem 4:404-419 
Bhaumk R, Mondal NK, Das B, Roy P, Pal KC, Das C, Banerjee A, Dutta JK (2012) Eggshell powder as an adsorbent for removal of fluoride from aqueous solution: equilibrium, kinetic and thermodynamic studies. E J Chem 9(3):1457-1480

Boparai HK, Joseph M, Carroll DMO (2011) Kinetics and thermodynamics of cadmium ion removal by adsorption onto nano zerovalent iron particles. J Hazard Mater 186:458-465

Can MY, Kaya Y, Algur OF (2006) Response surface optimization of removal of nickel from aqueous solution by cone biomass of Pinus sylvestris. Bioresour Technol 97:1761-1765

Chakrabarty S, Sarma HP (2012) Defluoridation of contaminated drinking water using neem charcoal adsorbent: kinetics and equilibrium studies. Int J ChemTech Res 4(2):511-516

Chattoraj S, Mondal NK, Das B, Roy P, Sadhukhan B (2014) Biosorption of carbaryl from aqueous solution onto Pistia stratiotes biomass. Appl Water Sci 4:79-88

Chen N, Zhang Z, Feng C, Li M, Zhu D, Chen R, Sugiura N (2010) An excellent fluoride sorption behaviour of ceramic adsorbent. J Hazard Mater 183:460-465

Choy KHK, McKay G, Porter JF (1999) Adsorption of acid dyes from effluents using activated carbon. Resour Conserv Recycl 27(1-2):57-71

Coetzee PP, Coetzee LL, Puka R, Mubenga S (2003) Characterisation of selected South African clays for defluoridation of natural waters. Water SA 29(3):331-338

Daifullah AAM, Yakout SM, Elreefy SA (2007) Adsorption of fluoride in aqueous solutions using $\mathrm{KMnO}_{4}$-modified activated carbon derived from steam pyrolysis of rice straw. J Hazard Mater 147:633-643

Díaz-Nava C, Olguín MT, Solache-Ríos M (2007) Water defluoridation by Mexican heulandite-clinoptilolite. Sep Sci Technol 37:3109-3128

Erdem M, Altundogan HS, Turner F (2004) Removal of hexavalent chromium by using heat activated bauxite. Miner Eng 17:1045-1052

Foo KY, Hameed BH (2010) Insights into the modeling of adsorption isotherm systems. Chem Eng J 156:2-10

Freundlich H (1906) Over the adsorption in solution. J Phys Chem 57(A):385

Ghorai S, Pant K (2005) Equilibrium, kinetics and breakthrough studies for adsorption of fluoride on activated alumina. Sep Purif Technol 42(3):265-271

Gomoro K, Zewge F, Hundhammer B, Megersa N (2012) Fluoride removal by adsorption on thermally treated lateritic soils. Bull Chem Soc Ethiop 26(3):361-372

Hanafiah MAK, Zakaria H, Wan Ngah WS (2009) Preparation, characterization, and adsorption behavior of $\mathrm{Cu}$ (II) ions on to alkali-treated weed (Imperata cylindrica) leaf powder. Water Air Soil Pollut 201:43-53

Hernández-Montoyaa V, Ramírez-Montoyaa LA, Bonilla-Petriciolet A, Montes-Moránb MA (2012) Optimizing the removal of fluoride from water using new carbons obtained by modification of nut shell with a calcium solution from egg shell. Biochem Eng J 62:1-7

Ho YS, McKay G, Wase DAJ, Forster CF (2000) Study of the sorption of divalent metal ions on to peat. Adsorpt Sci Technol 18(7):639-650

Ho YS, Porter JF, McKay G (2002) Equilibrium isotherm studies for the sorption of divalent metal ions onto peat: copper, nickel and lead single component systems. Water Air Soil Pollut 141:1-33

Johnson RD, Arnold FH (1995) The Temkin isotherm describes heterogeneous protein adsorption. Biochem Biophys Acta 1247(2):293-297

Karthikeyan G, Ilango S (2007) Fluoride sorption using Morringa indica-based activated carbon. Iran J Environ Health Sci Eng $4(1): 21-28$
Karthikeyan S, Balasubramanian R, Iyer CSP (2007) Evaluation of the marine algae Ulva asciata and Sargassum sp. for the biosorption of $\mathrm{Cu}$ (II) from aqueous solutions. Biores Technol 98:452-455

Kumar S, Gupta A, Yadav JP (2007) Fluoride removal by mixtures of activated carbon prepared from neem (Azadirachta indica) and kikar (Acacia arabica). Indian J Chem Technol 14:355-361

Lagergren S (1898) Zurtheorie der Sogenannten adsorption gelster stoffe, Kungliga Sevenska Vetenskapsakademiens. Handlingar 24(4):1-39

Langmuir I (1918) The adsorption of gases on plane surface of glass, mica, and platinum. J Am Chem Soc 40:1361-1403

Magdy YH, Daifullah AAM (1998) Adsorption of a basic dye from aqueous solutions onto sugar-industry-mud in two modes of operations. Waste Manag 18(4):219-226

Mahramanlioglu M, Kizilcikli I, Bicer I (2002) Adsorption of fluoride from aqueous solution by acid treated spent bleaching earth. J Fluor Chem 115:41-47

Mariappan P, Yegnaraman V, Vasudevan T (2003) Occurrence and removal possibilities of fluoride in groundwater of India. Pollut Res 19:165-177

Meenakshi A, Maheshwari RC (2006) Fluoride in drinking water and its removal. J Hazard Mater 137:456

Memon JR, Memon SQ, Bhanger MI, Khuhawar MY (2008) Banana peel: a green and economical sorbent for $\mathrm{Cr}$ (III) removal. Pak J Anal Environ Chem 9(1):20-25

Mondal MK (2010) Removal of $\mathrm{Pb}$ (II) from aqueous solution by adsorption using activated tea waste. Korean J Chem Eng 27:144-151

Mondal NK, Das B, Bhaumik R, Bour T, Roy P (2012a) Calcareous soil as a promising adsorbent to remove fluoride from aqueous solution: equilibrium, kinetic and thermodynamic study. J Mod Chem Technol 3(3):1-21

Mondal NK, Bhaumik R, Bour T, Das B, Roy P, Datta JK (2012b) Studies on defluoridation of water by tea ash: an unconventional biosorbent. Chem Sci Trans 1(2):239-256

Mondal NK, Bhaumik R, Banerjee A, Datta JK, Baur T (2012c) A comparative study on the batch performance of fluoride adsorption by activated silica gel and activated rice husk ash. Int $\mathbf{J}$ Environ Sci 2(3):1643-1661

Mondal NK, Bhaumik R, Roy P, Das B, Datta JK (2013) Investigation on fixed bed column performance of fluoride adsorption by sugarcane charcoal. J Environ Bio 34:1059-1064

Myers RH, Montgomery DC (2002) Response surface methodology, 2nd edn. Wiley, New York

Ng JCY, Cheung WH, McKay G (2002) Equilibrium studies of the sorption of $\mathrm{Cu}$ (II) ions onto chitosan. J Colloid Interface Sci 255:64-74

Rengaraj S, Yeon JW, Kim Y, Kim WH (2007) Application of Mgmesoporous alumina prepared by using magnesium stearate as a template for the removal of nickel: kinetics, isotherm, and error analysis. Ind Eng Chem Res 46:2834-2842

Roy P, Mondal NK, Das K (2014) Modeling of the adsorptive removal of arsenic: a statistical approach. J Environ Chem Eng 2:585-597

Sahu JN, Acharya J, Meikp BC (2009) Response surface modeling and optimization of chromium (VI) removal from aqueous solution using tamarind wood activated carbon in batch process. J Hazard Mater 172(2-3):818-825

Shahjee P, Godboley BJ, Sudame AM (2013) Removal of fluoride from aqueous solution by using low cost adsorbent. Int $\mathrm{J}$ Innov Res Sci Eng Technol 2(7):2721-2725

Singh KP, Ojha P, Malik A, Jain G (2009) Partial least squares and artificial neural networks modeling for predicting chlorophenol removal from aqueous solution. Chemom Intell Lab Syst 99:150-160 
Singh J, Mishr NS, Uma, Banerjee S, Sharma YC (2011) Comparative studies of physical characteristics of raw and modified saw dust for their use as adsorbents for removal of acid dye. Bio Resour 6(3):2732-2743

Srivastava VV, Swamy MM, Mal ID, Prasad B, Mishra IM (2006) Adsorptive removal of phenol by bagasse fly ash and activated carbon: equilibrium, kinetics and thermodynamics. Colloids Surf 272:89-104

Stipp SLS (1999) Toward a conceptual model of the calcite surface: hydration, hydrolysis, and surface potential. Geochem Cosmochim Acta 63:3121-3131

Sujana MG, Anand S (2010) Fluoride removal studies from contaminated ground water by using bauxite. Desalination 267(2-3): 222-227

Tan AW, Ahmad AL, Hameed BH (2008) Adsorption of basic dye on high-surface-area activated carbon prepared from coconut husk: equilibrium, kinetic and thermodynamic studies. J Hazard Mater 154:337-346

Tchomgui-Kamga E, Ngameni E, Darchen A (2010) Evaluation of removal efficiency of fluoride from aqueous solution using new charcoals that contain calcium compounds. J Colliod Interface Sci 346:494-499
Tomar V, Kumar D (2013) A critical study on efficiency of different materials for fluoride removal from aqueous media. Chem Cent J 7(51):2-15

Tor A, Danaoglua N, Arslan G, Cengeloglu Y (2009) Removal of fluoride from water by using granular red mud: batch and column studies. J Hazard Mater 164:271-278

Turner BD, Binning PJ, Sloan SW (2010) Impact of phosphate on fluoride removal by calcite. Environ Eng Sci 27(8):643-650

Weber WJ, Morris JC (1963) Kinetics of adsorption on carbon from solution. J Sanit Eng Div Am Soc Civil Eng 89:31

WHO (2008) International standards for drinking water, 3rd edn. Geneva

WHO (World Health Organization) (2004) Guidelines for drinking water quality. World Health Organization, Geneva

Yadav AK, Kaushik CP, Haritash AK, Kansal A, Rani N (2006) Defluoridation of groundwater using brick powder as an adsorbent. J Hazard Mater 128:289-293

Yadav AK, Abbassi R, Gupta A, Dadashzadeh M (2013) Removal of fluoride from aqueous solution and groundwater by wheat straw saw dust and activated carbon of sugarcane. Ecol Eng $52: 211-218$ 